OPEN ACCESS

Edited by:

Qizhao Wang,

Northwest Normal University, China

Reviewed by:

Yanhui Ao,

Hohai University, China

Xufang Qian,

Shanghai Jiao Tong University, China

Mingshan Zhu,

Jinan University, China

*Correspondence:

Mingyang Xing

mingyangxing@ecust.edu.cn

Jinlong Zhang

jlzhang@ecust.edu.cn

Specialty section:

This article was submitted to

Catalytic Remediation,

a section of the journal

Frontiers in Environmental Chemistry

Received: 08 July 2020

Accepted: 11 August 2020

Published: 22 September 2020

Citation:

Dong C, Xing M and Zhang J (2020)

Recent Progress of Photocatalytic

Fenton-Like Process for

Environmental Remediation.

Front. Environ. Chem. 1:8.

doi: 10.3389/fenvc.2020.00008

\section{Recent Progress of Photocatalytic Fenton-Like Process for Environmental Remediation}

\author{
Chencheng Dong, Mingyang Xing * and Jinlong Zhang*
}

Key Laboratory for Advanced Materials and Joint International Research Laboratory of Precision Chemistry and Molecular Engineering, Feringa Nobel Prize Scientist Joint Research Center, Frontiers Science Center for Materiobiology and Dynamic Chemistry, School of Chemistry and Molecular Engineering, East China University of Science and Technology, Shanghai, China

Over the past few decades, Fenton process has been widely studied in environmental remediation. Due to the low efficiency of iron ions recycling, the Fenton efficiency has been seriously impeded for practical application. On this condition, with combination of photocatalysts, it is expected to fully use photo-generated electrons, thus enhancing the photo-Fenton efficiency. This synergistic methodology has assisted many researchers to remove various categories of organic pollutants in discharged wastewater or achieve gas conversion. This comprehensive review describes some significant advances with respect to presentative semiconductors (e.g., $\mathrm{TiO}_{2}, \mathrm{~g}-\mathrm{C}_{3} \mathrm{~N}_{4}$, graphene, $\mathrm{BiVO}_{4}, \mathrm{ZnFeO}$ and $\mathrm{BiFeO}_{3}$, etc.) including their preparation methods, characterization and applications in environmental remediation (e.g., organic removal, bacteria disinfection, membrane separation, and gas conversion). The mechanism is preferentially discussed. Possibly future development and its correlated potential challenges are specifically proposed and discussed in this review.

Keywords: photocatalytic Fenton reaction, organic pollutant degradation, disinfection, volatile organic compound (VOC), membrance

\section{INTRODUCTION}

In recent decades, the aqueous environment arising from a great variety of contaminants, for instance, emerging contaminants (ECs) including pharmaceuticals and personal care products (PPCPs), dyes, endocrine-disrupting compounds (EDCs), flame retardants (FRs), pesticides, and their metabolites pose a major concern to human beings (Esplugas et al., 2007; Klamerth et al., 2013). Although their concentration in real sewage is in the $\mu \mathrm{g} \mathrm{L}^{-1}-\mathrm{ng} \mathrm{L} \mathrm{L}^{-1}$ range, they unconsciously discharge into the environment and biologically accumulate in human body, thus posing a severe threat to receiving waters (e.g., rivers, aquifers and groundwater) (Zhang et al., 2014). To the best of our knowledge, conventional wastewater treatment plants (WWTP) are often unable to entirely degrade persistent organic pollutants (Jelic et al., 2011; Klamerth et al., 2013). Consequently, the pollutants and their metabolites accumulate in the aquatic environment, indirectly they may cause ecological risk. As a result, the alternatively advanced technique is of paramount importance to be developed.

Advanced oxidation processes (AOPs), which have been proposed as replaceable solutions for degrading persistent organic compounds, because the hydroxyl radicals $(\cdot \mathrm{OH})$ are 


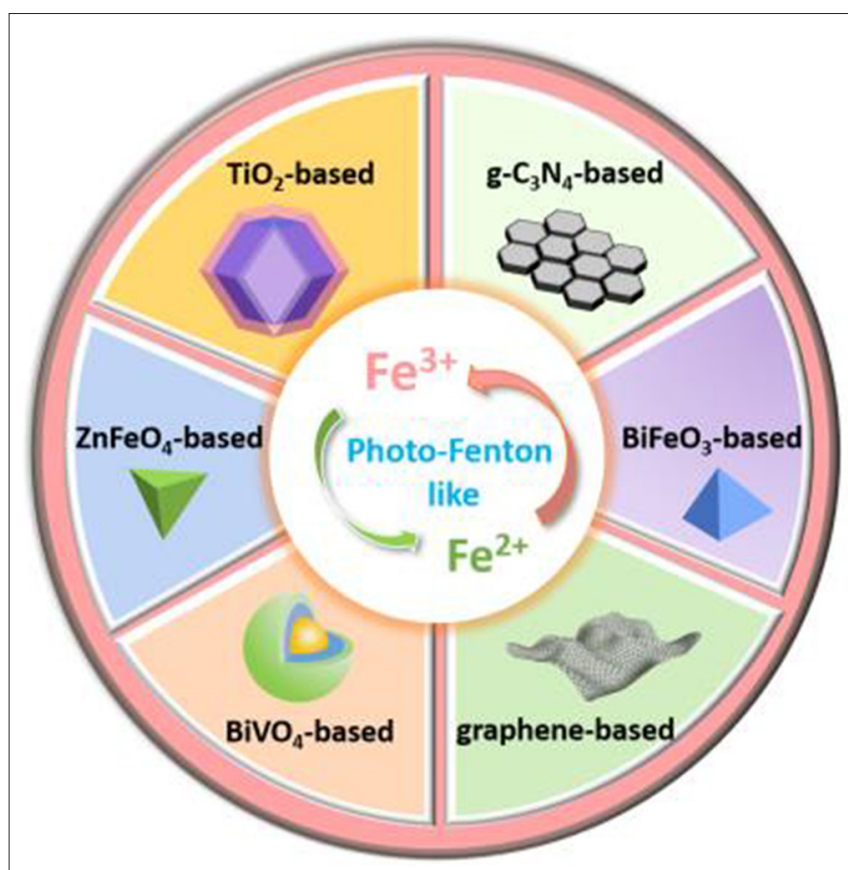

Graphical Abstract | Semiconductor-based photo-Fenton like nanomaterials.

unselectively promote organic substances oxidation at high reaction rates (Zhang et al., 2009; Sun et al., 2020). Besides this, AOPs are also called as versatile technologies owing to the various alternative ways in generation hydroxyl radicals (Lee and von Gunten, 2010). In comparison with conventional treatment techniques, AOPs are more efficient and capable of degrading recalcitrant pollutants. In AOPs, a variety of oxidants such as hydrogen peroxide $\left(\mathrm{H}_{2} \mathrm{O}_{2}\right)$ (Dong C. et al., 2018; Xing et al., 2018a), persulfate (Matzek and Carter, 2016; Wang and Wang, 2018), peroxymonosulfate (Shao et al., 2017; Tan et al., 2017; Duan et al., 2018; Lei et al., 2019; Ma et al., 2019; Shen et al., 2019), permanganate (Guo et al., 2018; Chow and Sze-Yin Leung, 2019; Wang et al., 2019), and ozone $\left(\mathrm{O}_{3}\right)$ (Khan et al., 2017; Ikehata and $\mathrm{Li}, 2018$ ) have been employed to degrade organic matters. Among these oxidants, $\mathrm{H}_{2} \mathrm{O}_{2}$ has been widely recognized as economically and environmentally friendly oxidant, according to its high efficacy and environmental friendliness.

In short, the combination of $\mathrm{Fe}^{2+}$ and $\mathrm{H}_{2} \mathrm{O}_{2}$ are called conventional Fenton reaction, which belong to a type of classical AOPs. Since 1894, H.J.H Fenton proposed the concept of Fenton process, he found that $\mathrm{Fe}^{2+}$ and $\mathrm{H}_{2} \mathrm{O}_{2}$ could degrade tartaric acid. Thus, it has been widely used in environmental remediation in the following decades (Jain et al., 2018). As the merits of Fenton progress, it is normally operated under ambient temperature and pressure (Qian et al., 2017, 2018a), and generate strongly oxidizing radical species (primarily $\cdot \mathrm{OH}$ ) for the complete decomposition of organic pollutants into non-toxic products, such as $\mathrm{CO}_{2}, \mathrm{H}_{2} \mathrm{O}$ and inorganic salts (Dong C. et al., 2018). Besides this, the advantages of Fenton process over other WWTPs are extremely superior, including of higher removal efficiency, no residues and wide region for treating substances as well as no need of special equipment. The conventional Fenton mechanism, which is involved with $\mathrm{Fe}^{2+} / \mathrm{H}_{2} \mathrm{O}_{2}$, is exhibited as the following equations:

$$
\begin{aligned}
& \mathrm{Fe}^{2+}+\mathrm{H}_{2} \mathrm{O}_{2} \rightarrow \mathrm{Fe}^{3+}+\mathrm{OH}^{-}+\cdot \mathrm{OH} \quad \mathrm{k}_{1}=40 \sim 80 \mathrm{~L} \cdot \mathrm{mol}^{-1} \cdot \mathrm{S}^{-1} \\
& \mathrm{Fe}^{3+}+\mathrm{H}_{2} \mathrm{O}_{2} \rightarrow \mathrm{Fe}^{2+}+\cdot \mathrm{O}_{2} \mathrm{H}^{-}+\mathrm{H}^{+} \mathrm{k}_{2}=9.1^{*} 10^{-7} \mathrm{~L} \cdot \mathrm{mol}^{-1} \cdot \mathrm{S}^{-1} \\
& \mathrm{Fe}^{3+}+\cdot \mathrm{O}_{2} \mathrm{H}^{-} \rightarrow \mathrm{Fe}^{2+}+\mathrm{O}_{2}+\mathrm{H}^{+} \quad \mathrm{k}_{3}=0.33 \sim 2.1^{*} 10^{6} \mathrm{~L} \cdot \mathrm{mol}^{-1} \cdot \mathrm{S}^{-1}
\end{aligned}
$$

However, the conventional decomposition efficiency of $\mathrm{H}_{2} \mathrm{O}_{2}$ in $\mathrm{Fe}^{2+} / \mathrm{H}_{2} \mathrm{O}_{2}$ system is constrained by the low $\mathrm{Fe}^{3+} / \mathrm{Fe}^{2+}$ cycle, owing to the low reaction rate constant of Equation (2). Therefore, the key to enhance the Fenton efficiency is accelerating the reaction constant of Equation (2); meanwhile, the iron sludge will be greatly reduced due to the high efficacy of $\mathrm{Fe}^{3+} / \mathrm{Fe}^{2+}$ cycle.

Besides Fenton process, photocatalytic oxidation has been considered as alternative and efficient AOP as well. Photocatalysis based AOPs initiate the complex chain reactions, and it may produce the colorless organic intermediates. Correspondingly, these colorless intermediates maybe more toxic than the parent molecular. Additionally, all of the Fenton reactions including conventional Fenton process and Fenton-like or photo-Fentonlike process easily produce iron mud, and it needs a large amount of manpower and chemicals to treat and remove iron mud. Thus, to achieve a thorough mineralization of organic compound is the main goal of AOPs in environmental remediation. After retrospection of the past few decades, it can be found that many studies have utilized the nano-photocatalysts for the degradation of organic pollutants; however, the utilization efficiency of photo-generated electrons and holes still remains a challenge for researchers in WWTPS. Based on this background information, many researchers have coupled Fenton reaction with photocatalysis as a novel technique to treat wastewater, which can be assigned to novel Fenton-like reaction. By means of this, it is able to realize a win-win situation. To be more specific, it can not only prolong the lifetime of photo-generated carries [i.e., photo electrons $\left(\mathrm{e}^{-}\right)$and hole $\left.\left(\mathrm{h}^{+}\right)\right]$, but also the photo-generated electrons will accelerate the cycle of $\mathrm{Fe}^{3+} / \mathrm{Fe}^{2+}$, leading to higher mineralization of pollutant and the reduction of iron sludge.

In this paper, we mainly review and summary several representative nanomaterials, which have been applied in photocatalytic Fenton reaction, including of $\mathrm{TiO}_{2}$-based, g$\mathrm{C}_{3} \mathrm{~N}_{4}$-based, reduced graphene oxide (RGO)-based and other semiconductors-based nanomaterials (e.g., Ag, $\mathrm{BiVO}_{4}, \mathrm{ZnFeO}_{4}$, and $\mathrm{BiFeO}_{3}$ based nanomaterials). This review mainly aims to review the nanomaterials based AOPs that are used for degradation of different organic pollutants in wastewater or volatile organic compounds (VOCs) removal and provide some effective information for developing latest solution of WWTPs.

\section{$\mathrm{TiO}_{2}$-BASED PHOTOCATALYTIC FENTON REACTION}

\section{Removing Organic Pollutant}

Since 1972, Fujishima and Honda (1972) found that titanium oxide $\left(\mathrm{TiO}_{2}\right)$ could split water to produce hydrogen under UV light irradiation, thus opening up a new era of titanium oxide $\left(\mathrm{TiO}_{2}\right)$ in photocatalysis. Up to now, $\mathrm{TiO}_{2}$ has been 
TABLE 1 | Summary of $\mathrm{TiO}_{2}$ based heterogeneous photo-Fenton and photo-Fenton like process under light irradiation.

\begin{tabular}{|c|c|c|c|c|c|c|c|c|}
\hline Catalyst & Target pollutant & $\mathrm{pH}$ & Catalyst dose & $\mathrm{H}_{2} \mathrm{O}_{2}$ dose & $\begin{array}{l}\text { Reaction } \\
\text { time }\end{array}$ & Light source & Decolorization & References \\
\hline $\mathrm{ZnSe} / \mathrm{TiO}_{2}$ & $\begin{array}{l}10 \mathrm{mg} / \mathrm{L} \\
\text { pentachlorophenol }\end{array}$ & 5.0 & $100 \mu \mathrm{M} \mathrm{Fe}^{3+}$ & $75 \mu \mathrm{M}$ & $120 \mathrm{~min}$ & Solar light & 99\% discoloration & $\begin{array}{l}\text { ThanhThuy et al., } \\
2013\end{array}$ \\
\hline Fe-VT & $100 \mathrm{mg} / \mathrm{L}$ orange X-GN & 3.0 & $0.5 \mathrm{~g} / \mathrm{L}$ & $3.92 \mathrm{mM}$ & $80 \mathrm{~min}$ & UV light & $\begin{array}{l}98.7 \% \\
\text { discoloration, } 54.4 \% \\
\text { TOC removal }\end{array}$ & Chen et al., 2010 \\
\hline $\mathrm{TiO}_{2}$ & $\begin{array}{l}40 \text { ppm } \\
\text { 3-chloropyridine }\end{array}$ & 2.8 & $\begin{array}{l}0.88 \mathrm{mM} \mathrm{Fe}{ }^{2+} \\
700 \mathrm{mg} / \mathrm{L} \mathrm{TiO}_{2}\end{array}$ & $8.8 \mathrm{mM}$ & $60 \mathrm{~min}$ & UV light & $100 \%$ TOC removal & $\begin{array}{l}\text { Ortega-Liébana } \\
\text { et al., } 2012\end{array}$ \\
\hline $\mathrm{TiO}_{2}$ & $\begin{array}{l}0.1 \mathrm{mM} \text { phenol and } \\
\text { benzoic acid }\end{array}$ & 6.0 & $\begin{array}{l}0.25 \mathrm{mM} \mathrm{Fe}(\mathrm{III}) \\
1.0 \mathrm{~g} / \mathrm{L} \mathrm{TiO}_{2}\end{array}$ & $10 \mathrm{mM}$ & $120 \mathrm{~min}$ & UV light & phenol 100\%, BA: 96\% & Kim et al., 2012 \\
\hline $\mathrm{Fe}-\mathrm{TiO}_{2}$ & $\begin{array}{l}2.1 \times 10^{-4} \mathrm{~mol} \mathrm{~L}^{-1} \\
\text { phenol }\end{array}$ & 6.4 & $0.2 \mathrm{~g} / \mathrm{L}$ & $0.015 \mathrm{mM}$ & $300 \mathrm{~min}$ & UV light & $20 \%$ & Tryba et al., 2006 \\
\hline $\mathrm{Fe}-\mathrm{C}-\mathrm{TiO}_{2}$ & $\begin{array}{l}2.1 \times 10^{-4} \mathrm{~mol} \\
\mathrm{~L}^{-1} \text { phenol }\end{array}$ & 2.8 & $0.2 \mathrm{~g} / \mathrm{L}$ & $0.015 \mathrm{mM}$ & $120 \mathrm{~min}$ & UV light & $\begin{array}{l}98 \% \text { degradation } \\
\text { removal }\end{array}$ & Tryba et al., 2006 \\
\hline $\mathrm{Fe}-\mathrm{TiO}_{2}$ & $0.32 \mathrm{mM}$ thiacloprid & 2.8 & $1.67 \mathrm{~g} / \mathrm{L}$ & $45 \mathrm{mM}$ & $500 \mathrm{~min}$ & UV light & $100 \%$ TOC removal & Banić et al., 2011 \\
\hline CdS/MWCNT-TiO 2 & 50 mM methylene blue & 3.5 & $0.75 \mathrm{~g} / \mathrm{L}$ & $0.6 \mathrm{mM}$ & $120 \mathrm{~min}$ & Visible light & $\begin{array}{l}98 \% \text { discoloration and } \\
83 \% \text { TOC removal }\end{array}$ & $\begin{array}{l}\text { Kim and Kan, } \\
2015\end{array}$ \\
\hline
\end{tabular}

well-applied in the fields of energy and environment, including organic removal (Vaiano et al., 2015; Shayegan et al., 2018; Chen et al., 2019; Dong et al., 2019), hydrogen production (Zhang et al., 2012; Xi et al., 2014; Xing et al., 2015; Zhou Y. et al., 2016), $\mathrm{CO}_{2}$ reduction (Yu et al., 2014; Dong et al., 2018a; Xing et al., 2018b), nitrogen fixation (Comer and Medford, 2018; Li C. et al., 2018; Zhao et al., 2019), and methane conversion (Wang P. et al., 2017; Yu et al., 2017), etc. Attributed to the sufficiently high reduction potential, low economical cost and high stability, $\mathrm{TiO}_{2}$ has attracted great attention as one of the most potential and influential photocatalysts (Dong et al., 2018b). In terms of photocatalytic Fenton reaction, especially, $\mathrm{TiO}_{2}$ based nanomaterials have been developed. Consequently, PhotoFenton oxidation process employed modified $\mathrm{TiO}_{2}, \mathrm{Fe}^{2+}$ or $\mathrm{Fe}^{3+}$, and $\mathrm{H}_{2} \mathrm{O}_{2}$ under light irradiation, leading to significant improved generation of hydroxyl radicals and degradation efficiency of organic pollutants owing to synergy between photocatalysis and Fenton reaction. Some examples have been summarized in Table 1.

In Table 1, we have listed some representative work in recent years. In 2012, Ortega-Liébana et al. (2012) developed $\mathrm{Fe}^{2+} / \mathrm{TiO}_{2} / \mathrm{H}_{2} \mathrm{O}_{2} / \mathrm{UV}$ system for the degradation of $40 \mathrm{ppm} 3-$ chloropyridine. The results showed that photo-Fenton process is more efficient than sole $\mathrm{TiO}_{2}$ photocatalysis, which meant that this technique possessed more practical industrialized application than photocatalysis. As to some modified $\mathrm{TiO}_{2}$ nanomaterials, for instance, Tryba et al. (2006) prepared Fe$\mathrm{TiO}_{2}$ and $\mathrm{Fe}-\mathrm{C}-\mathrm{TiO}_{2}$ nanomaterials, which could effectively degrade phenol. The highly efficient decomposition of phenol on $\mathrm{Fe}-\mathrm{C}-\mathrm{TiO}_{2}$ photocatalysts mainly attributed from several factors: (1) the produced hydroxyl radicals in Fenton process; (2) the reduction of $\mathrm{Fe}^{3+}$ back to $\mathrm{Fe}^{2+}$ under UV light; (3) the cocatalytic effect of hydroquinone. Additionally, Banić et al. (2011) prepared $\mathrm{Fe} / \mathrm{TiO}_{2}$ materials with various loading amount of $\mathrm{Fe}_{2} \mathrm{O}_{3}$ nanoparticles. The $7.2 \mathrm{Fe} / \mathrm{TiO}_{2} / \mathrm{H}_{2} \mathrm{O}_{2}$ system exhibited the highest activity for removing TCL among all the used AOPs (Figures 1A,B). In Figure 1A, it could be observed that $1.67 \mathrm{~g} \mathrm{~L}^{-1} 7.2 \mathrm{Fe} / \mathrm{TiO}_{2} / 45 \mathrm{H}_{2} \mathrm{O}_{2}$ system achieved $100 \%$ removal efficiency after $25 \mathrm{~min}$. However, in this case, $\mathrm{TiO}_{2}$ only acted as a good support, because the degradation efficiency of $7.2 \mathrm{Fe} / \mathrm{TiO}_{2}$ is lower compared to the $\mathrm{TiO}_{2}$ support, indicating the presence of Fe under UV irradiation did not contribute to the catalytic activity of the material, and not facilitating the cycle of $\mathrm{Fe}^{3+} / \mathrm{Fe}^{2+}$. Moreover, the results indicated that the removal efficiency was influenced by some possible parameters including $\mathrm{pH}$ and TCL concentrations (Figures 1C,D). In Figure 1C, the optimal $\mathrm{pH}$ value was fixed at 2.8. As to TCL concentrations, when TCL concentration exceeded $0.12 \mathrm{mM}$, the reaction rate tended to slow down (Figure 1D), ascribed to that most of the $7.2 \mathrm{Fe} / \mathrm{TiO}_{2}$ active sites were occupied, leading to reduced generation of reactive oxygen species.

When it comes to coupled semiconductor, ThanhThuy et al. (2013) prepared $\mathrm{ZnSe} / \mathrm{TiO}_{2}$ nanocomposites. Under simulated solar light, the $\mathrm{ZnSe}$ sensitized $\mathrm{TiO}_{2}$ nanotube arrays exhibited remarkable capability for photocatalytic degradation of pentachlorophenol assisted with photo-Fenton system (i.e., $\mathrm{Fe}^{3+} / \mathrm{H}_{2} \mathrm{O}_{2} /$ humic acid). The results showed that $99.0 \%$ of pentachlorophenol could be degraded in comparison with pure $\mathrm{TiO}_{2}$ NTAs (64.0\%) after $2 \mathrm{~h}$ solar light irradiation. Further, Kim and Kan (2015) synthesized CdS/carbon nanotube$\mathrm{TiO}_{2}\left(\mathrm{CdS} / \mathrm{CNT}-\mathrm{TiO}_{2}\right)$, which was applied in heterogeneous photo-Fenton process as well. The heterogeneous photo-Fenton oxidation cocatalyzed by $\mathrm{CdS} / \mathrm{CNT}-\mathrm{TiO}_{2}$ was mainly engaged in the combination of the photocatalytic, photo-Fenton and photosensitizing oxidation. Consequently, the photo-Fenton process achieved a high decolorization (98\%) and mineralization rate $(83 \%)$. To the best of our knowledge, the concentration of ferrous and ferro ferric ion as well as hydrogen peroxide is of great necessary for enhancing treatment efficiency and minimizing operating costs. In Figure 2A, firstly, it was found 
A

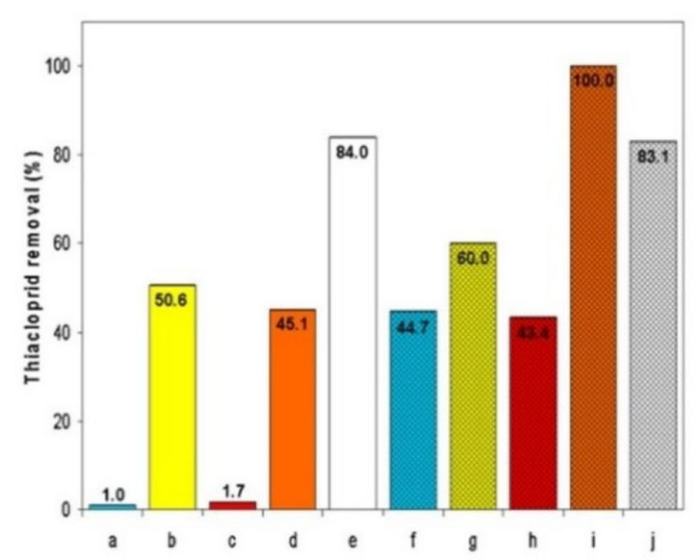

C

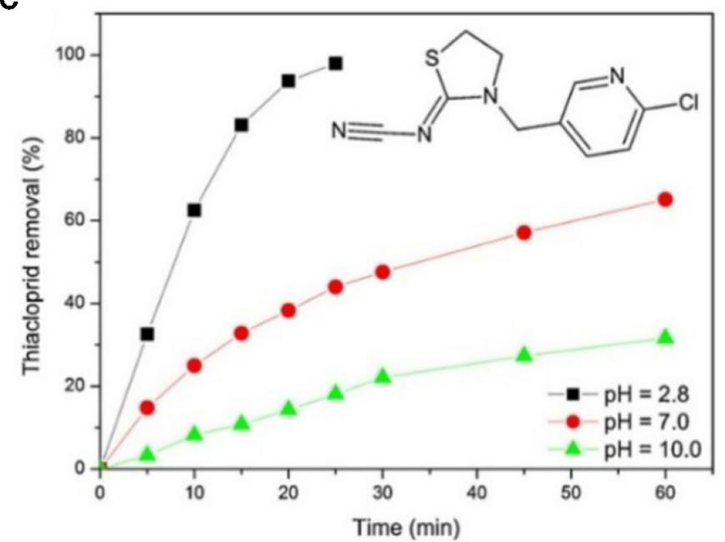

B

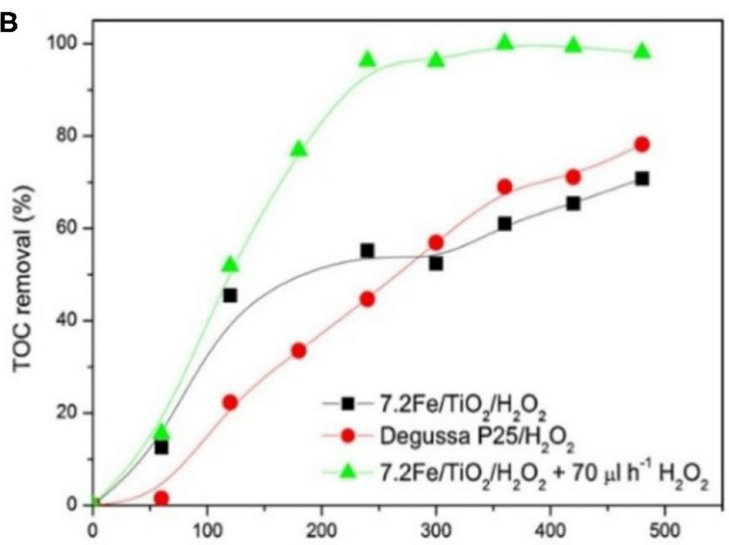

D

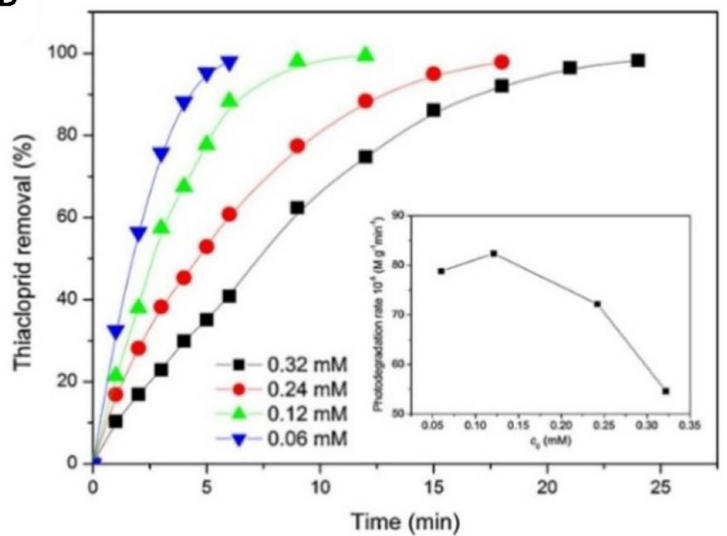

FIGURE 1 | (A) Photodegradation efficiency of various systems of TCL under UV light irradiation: (a) photolysis, (b) $\mathrm{TiO}_{2}$ support, (c) $\mathrm{PrecFe}$, (d) $7.2 \mathrm{Fe} / \mathrm{TiO}{ }_{2}$, (e) Degussa P25, (f) $\mathrm{H}_{2} \mathrm{O}_{2}$, (g) $\mathrm{TiO}_{2}$ support/ $\mathrm{H}_{2} \mathrm{O}_{2}$, (h) PrecFe/ $\mathrm{H}_{2} \mathrm{O}_{2}$, (i) $7.2 \mathrm{Fe} / \mathrm{TiO}_{2} / \mathrm{H}_{2} \mathrm{O}_{2}$, and (j) Degussa $\mathrm{P} 25 / 45 \mathrm{mM} \mathrm{H}_{2} \mathrm{O}_{2}$. (B) TOC removal efficiency for TCL in the presence of $7.2 \mathrm{Fe} / \mathrm{TiO}_{2}$ and Degussa P25, respectively. (C) Impact of $\mathrm{pH}$ value on the kinetic of TCL photodegradation efficiency. (D) Impact of TCL concentration on the kinetic photodegradation efficiency (inset picture: the impact of the TCL concentration on the TCL degradation rate at 6 min light irradiation). Copied with permission (Banić et al., 2011). Copyright 2011, Elsevier.

that degradation and TOC removal efficiency of MB can be increased to 99 and $83 \%$, respectively. Secondly, the ratio of $\left[\mathrm{Fe}^{3+}\right]:\left[\mathrm{H}_{2} \mathrm{O}_{2}\right]$ increased from 0.05 to 0.5 led to the $\mathrm{MB}$ removal efficiency to $100 \%$; meanwhile, the TOC removal efficiency could be increased from 61 to $84 \%$ (Figure 2B). The detailed mechanism has been proposed in Figure 2C. Specifically, the photo-induced electron $\left(\mathrm{e}_{\mathrm{cb}}^{-}\right)$on the surface of $\mathrm{TiO}_{2}$ can be scavenged by oxygen, whereas the photo-induced hole $\left(\mathrm{h}_{\mathrm{vb}}^{+}\right)$can react with $\mathrm{OH}^{-}$or $\mathrm{H}_{2} \mathrm{O}$. Afterwards, the electrons transferred to these adsorb $\mathrm{Fe}^{3+}$ ions on $\mathrm{TiO}_{2}$ surface, leading to the cycle of $\mathrm{Fe}^{3+} / \mathrm{Fe}^{2+}$. Simultaneously, the electron on $\mathrm{TiO}_{2}$ surface would possibly impede the electron-hole recombination. Lastly, MB molecular acting as photosensitizer would form $\mathrm{MB}^{*}$ under visible light irradiation. The electron transfer between the $\mathrm{MB}^{*}$ and $\mathrm{Fe}^{3+}$ would be beneficial to regenerating $\mathrm{Fe}^{2+}$, which accelerated the kinetic rate of the photo-Fenton process.

\section{Disinfection}

Apart from the organic pollutant removal, photo-Fenton process serving for water disinfection has emerged in recent decades.
Commonly, according to the rules, two main solutions are able to be adopted if researchers want to employ photo-Fenton process to bacterial inactivation, including of drinking water disinfection and secondary effluent from municipal wastewater treatment plants (MWWTPs) (Giannakis et al., 2016). In terms of the target microorganisms, especially E. coli K12, was mostly selected as studied target. Regarding $\mathrm{TiO}_{2}$ on disinfection, the earliest systematic study was reported mainly based on photocatalytic water disinfection for E. coli inactivation (Rincón and Pulgarin, 2004a,b). Afterwards, Rincón and Pulgarin (2006) compared $\mathrm{Fe}^{3+}$ and $\mathrm{TiO}_{2}$ assisted system. Several systems have been established (e.g., $\mathrm{UV}$-vis/ $/ \mathrm{TiO}_{2}, \mathrm{UV}$-vis/ $/ \mathrm{TiO}_{2} / \mathrm{H}_{2} \mathrm{O}_{2}$, $\mathrm{UV}$-vis $/ \mathrm{Fe}^{3+} / \mathrm{H}_{2} \mathrm{O}_{2}$, and $\mathrm{UV}$-vis $/ \mathrm{H}_{2} \mathrm{O}_{2}$ ). It was revealed that the disinfection rate of $\mathrm{TiO}_{2}$ could be accelerated if $\mathrm{H}_{2} \mathrm{O}_{2}$ existed. Herein, $\mathrm{TiO}_{2}$ itself can show disinfection efficiency of E. coli, acting as photocatalyst, which can produce hydroxyl radicals under UV-vis irradiation. After addition of $\mathrm{H}_{2} \mathrm{O}_{2}$, the photoinduced charge transfer will be effectively separated because $\mathrm{H}_{2} \mathrm{O}_{2}$ acting as electron acceptor, thus preventing the recombination of electron-hole pairs, and generating much 


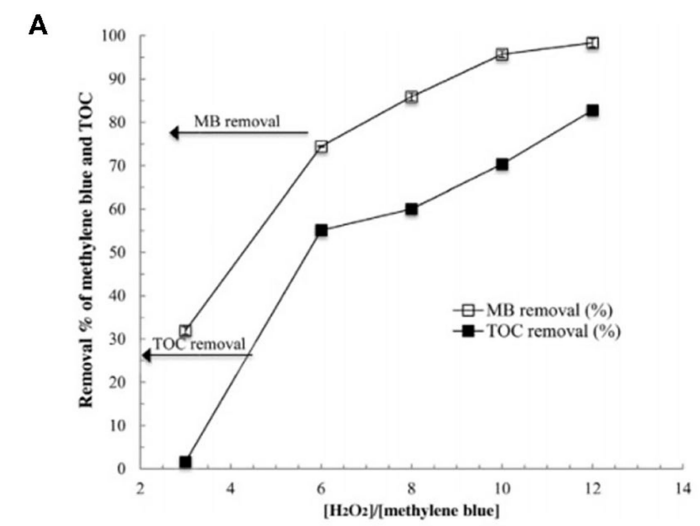

B

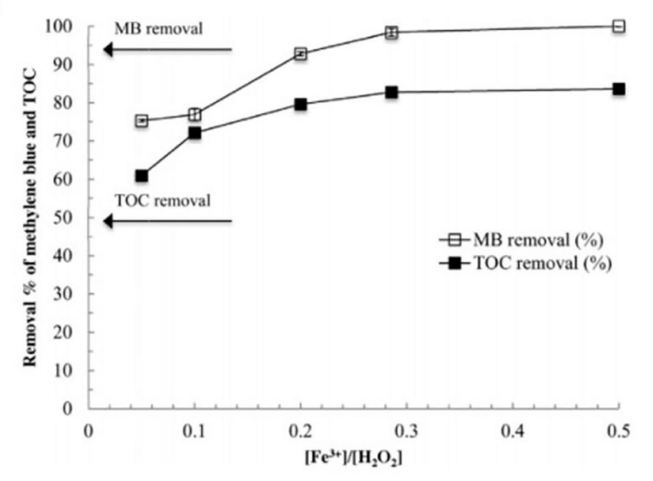

C

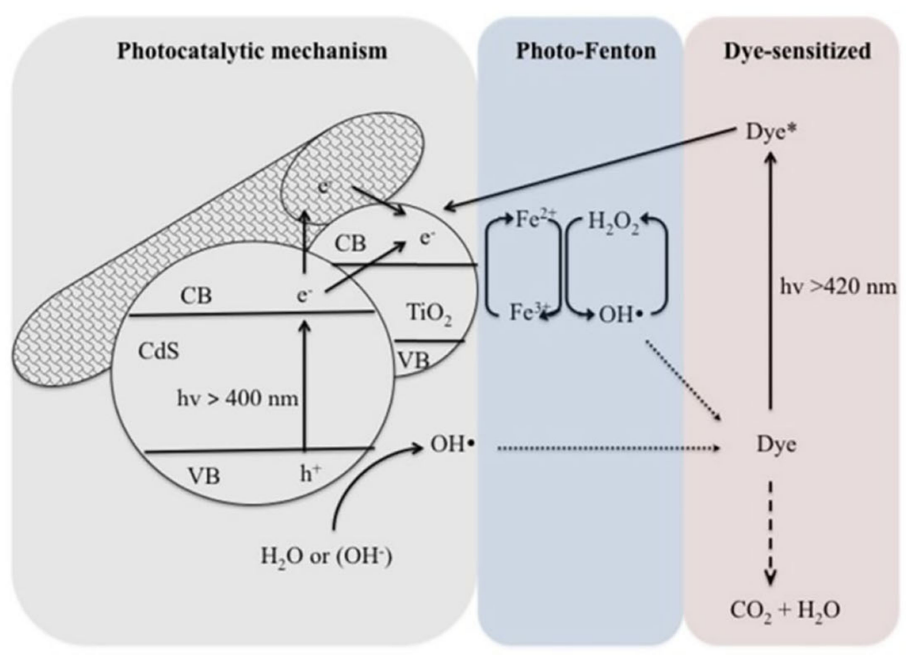

FIGURE 2 | (A) Impact of the ratio of $\left[\mathrm{H}_{2} \mathrm{O}_{2}\right] /[\mathrm{MB}]$ on photo-Fenton degradation efficiency of MB. (B) Impact of the ratio of $\left[\mathrm{Fe}^{3+}\right] /\left[\mathrm{H}_{2} \mathrm{O}_{2}\right]$ on photo-Fenton degradation efficiency of $\mathrm{MB}$. (C) Proposed mechanism of $\mathrm{CdS} / \mathrm{CNT}^{-T i \mathrm{O}_{2}}$ for photo-Fenton degradation of $\mathrm{MB}$ under visible light irradiation. Copied with permission (Kim and Kan, 2015). Copyright 2015, Elsevier.

more $\cdot \mathrm{OH}$ radicals. In Figure $\mathbf{3 A}$, it could be clearly seen that $\mathrm{TiO}_{2} / \mathrm{H}_{2} \mathrm{O}_{2}$ system is more efficient than $\mathrm{Fe}^{3+} / \mathrm{H}_{2} \mathrm{O}_{2}$ system. Compared to the dark controls in Figure 3B, the irradiation of solar light could promote the bacterial inactivation. $\mathrm{H}_{2} \mathrm{O}_{2}$ alone did not obviously impede the $E$. coli survival, whereas $\mathrm{TiO}_{2}$ could increase its bactericide oxidation ability.

In this section, $\mathrm{TiO}_{2}$ based nanomaterials have been briefly introduced in the field of organic pollutant removal and disinfection of bacteria in wastewater. Regarding of this, $\mathrm{TiO}_{2}$ based nanomaterial is expected to perform as well as in actual usage.

\section{g- $\mathrm{C}_{3} \mathrm{~N}_{4}$-BASED PHOTOCATALYTIC FENTON REACTION}

Due to the simple synthesis method, good physical and chemical stability and earth abundant characteristics, graphite carbonitride $\left(\mathrm{g}-\mathrm{C}_{3} \mathrm{~N}_{4}\right)$ has attracted scientists attention in terms of energy conversion and environmental remediation (Lan et al., 2019). As to homogeneous $\mathrm{Fe}^{2+} / \mathrm{H}_{2} \mathrm{O}_{2}$ Fenton process, the water-soluble $\mathrm{Fe}^{2+}$ catalyzed $\mathrm{H}_{2} \mathrm{O}_{2}$ to produce hydroxyl radical; however, traditional homogeneous catalysts will be constrained by the following drawbacks: (1) low decomposition efficiency of $\mathrm{H}_{2} \mathrm{O}_{2}$; (2) sludge residue; (3) limited $\mathrm{pH}$ value between 3.0 and 4.0 (Qian et al., 2018b). Overall, iron leaching issue has posed serious problem in acidic aquatic environment. Additionally, g- $\mathrm{C}_{3} \mathrm{~N}_{4}$ nanomaterials have emerged as a promising visiblelight-response photocatalyst in organic removal and water splitting (Dong H. et al., 2018; Safaei-Ghomi et al., 2019). In 2012, Cui et al. (2012) firstly reported that visible light excited of $\mathrm{g}-\mathrm{C}_{3} \mathrm{~N}_{4}$ catalyzed $\mathrm{H}_{2} \mathrm{O}_{2}$ to produce $\cdot \mathrm{OH}$ radicals. Successively, g- $\mathrm{C}_{3} \mathrm{~N}_{4}$ coupled with various types of Fe-based materials were explored for removing recalcitrant organic pollutants via photo-Fenton process, including of iron minerals (He et al., 2017), Fe(III) (Hu et al., 2016), single molecule iron complex (Chen et al., 2010; Banić et al., 2011), and iron oxide (Zhou L. et al., 2016; Wang et al., 2018) etc. Moreover, carbon nitride-based nanomaterials could serve as photo-Fenton-like membranes (Yu et al., 2018; Lan et al., 2019). Except of above mentioned, Li et al. (2016) constructed solid-gasinterfacial Fenton reaction over alkalinized- $\mathrm{C}_{3} \mathrm{~N}_{4}$ photocatalyst in isopropanol photodegradation. The specific illustration will be revealed in this section.

\section{Removing Organic Pollutant}

Regarding photo-Fenton degradation of refractory organic pollutants, notably, Zhou L. et al. (2016) has built a highly efficient visible-light-driven heterogeneous photo-Fenton system (i.e., $\mathrm{Fe}_{2} \mathrm{O}_{3} / g-\mathrm{C}_{3} \mathrm{~N}_{4} / \mathrm{H}_{2} \mathrm{O}_{2}$ ), which demonstrated that $\mathrm{Fe}_{2} \mathrm{O}_{3}$ nanoparticles were uniformly dispersed onto the surface of g$\mathrm{C}_{3} \mathrm{~N}_{4}$ (Figure 4A) and formed a heterojunction with $\mathrm{g}-\mathrm{C}_{3} \mathrm{~N}_{4}$ 


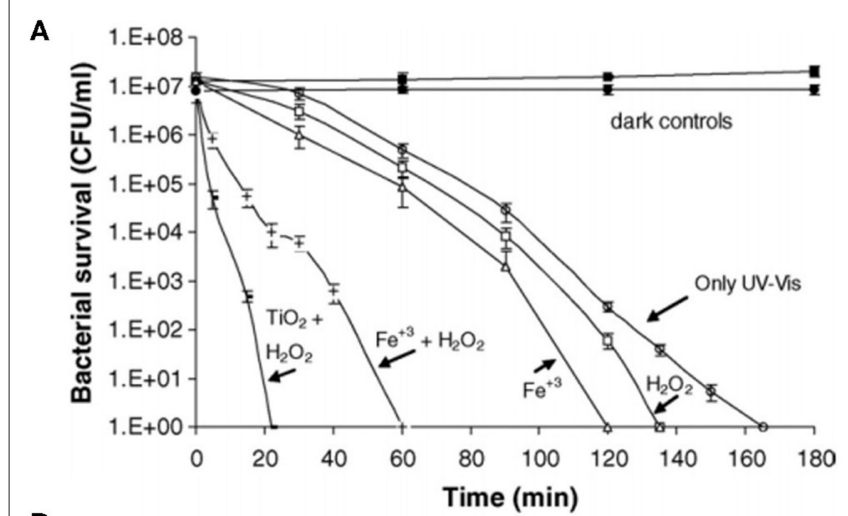

B

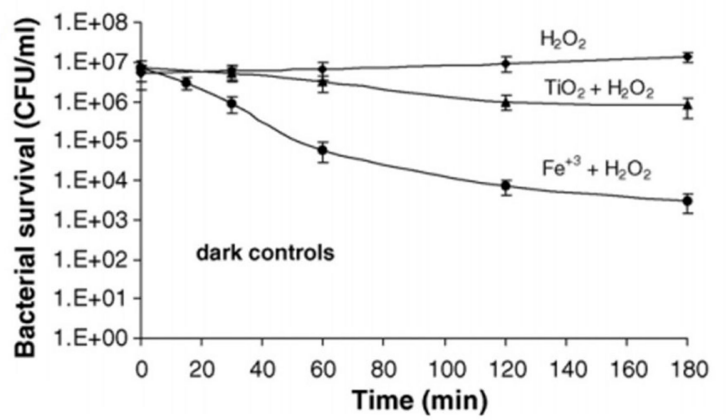

FIGURE 3 | (A) E. coli inactivation under different light driven AOPs systems including UV-vis $/ \mathrm{TiO}_{2} / \mathrm{H}_{2} \mathrm{O}_{2}$, UV-vis/ $/ \mathrm{Fe}^{3+} / \mathrm{H}_{2} \mathrm{O}_{2}, \mathrm{UV}$-vis $/ \mathrm{Fe}^{3+}, \mathrm{UV}$-vis $/ \mathrm{H}_{2} \mathrm{O}_{2}$, and only UV-vis. Dark controls: $\mathrm{Fe}^{3+}$ and $\mathrm{TiO}_{2}$. (B) E. coli survival under different dark systems including of $\mathrm{TiO}_{2} / \mathrm{H}_{2} \mathrm{O}_{2}, \mathrm{Fe}^{3+} / \mathrm{H}_{2} \mathrm{O}_{2}$, and $\mathrm{H}_{2} \mathrm{O}_{2}$ systems. Copied with permission (Rincón and Pulgarin, 2006). Copyright 2006, Elsevier.

to enhance the charge separation. It can be clearly observed that $\mathrm{Fe}_{2} \mathrm{O}_{3}$ nanoparticles uniformly dispersed onto g- $\mathrm{C}_{3} \mathrm{~N}_{4}$ nanosheets in comparison with pristine $\mathrm{g}-\mathrm{C}_{3} \mathrm{~N}_{4}$ (Figure $4 \mathrm{~B}$ ). As to degradation efficiency, the result was clarified in Figure 4C. The photo-Fenton capacity of $\mathrm{Fe}_{2} \mathrm{O}_{3} / g-\mathrm{C}_{3} \mathrm{~N}_{4}$ was investigated for removing $\mathrm{MO}$ aided by $\mathrm{H}_{2} \mathrm{O}_{2}$ under visible-light irradiation. From the figure curves, it can be obtained that all the $\mathrm{Fe}_{2} \mathrm{O}_{3} / g-$ $\mathrm{C}_{3} \mathrm{~N}_{4}$ exhibited superior degradation efficiency than pure $\mathrm{Fe}_{2} \mathrm{O}_{3}$ and $\mathrm{g}-\mathrm{C}_{3} \mathrm{~N}_{4}$ as well as $\mathrm{g}-\mathrm{C}_{3} \mathrm{~N}_{4}+\mathrm{Fe}_{2} \mathrm{O}_{3}$. The absorbance intensity of MO decreased gradually with time as shown in Figure 4D. Moreover, the kinetic constant of photo-Fenton degradation efficiency of $\mathrm{Fe}_{2} \mathrm{O}_{3} / g-\mathrm{C}_{3} \mathrm{~N}_{4}$ was determined as shown in Figure 4E. Significantly, the $k$-value of $\mathrm{Fe}_{2} \mathrm{O}_{3} / g-\mathrm{C}_{3} \mathrm{~N}_{4}$ is about 45.4 times higher than that of $\mathrm{Fe}_{2} \mathrm{O}_{3}, 8.4$ times higher than that of g- $\mathrm{C}_{3} \mathrm{~N}_{4}$ and 7.2 times than that of $\mathrm{g}-\mathrm{C}_{3} \mathrm{~N}_{4}+\mathrm{Fe}_{2} \mathrm{O}_{3}$, respectively. Based on experimental analysis, a possible mechanism is proposed in Figure 4F. Once irradiated with visible light, the electron-hole pairs will be produced from both of $\mathrm{Fe}_{2} \mathrm{O}_{3}$ and g$\mathrm{C}_{3} \mathrm{~N}_{4}$; meanwhile, the interfacial charge transfer promoted by the contact between $\mathrm{Fe}_{2} \mathrm{O}_{3}$ and $\mathrm{g}-\mathrm{C}_{3} \mathrm{~N}_{4}$ will further enhance the charge separation efficiency. The highly efficient efficiency not only arose from the photo-generated holes reacting with water molecular to produce hydroxyl radicals, but also the photoinduced electrons will be utilized to produce hydroxyl radicals. The generated electrons in the $\mathrm{CB}$ of $\mathrm{Fe}_{2} \mathrm{O}_{3}$ and transferred from the $\mathrm{CB}$ of $\mathrm{g}-\mathrm{C}_{3} \mathrm{~N}_{4}$ will contributed the conversion between $\mathrm{Fe}^{3+}$ and $\mathrm{Fe}^{2+}$. Overall, the generation rate of hydroxyl radicals which produced during Fenton process will be accelerated, thus leading to the enhancement of degradation efficiency. In addition, the fully consumption of photo-induced electrons during Fenton process will ulterior promote the charge separation, introducing more holes devoting to degradation process. Lastly, the catalytic activity can be greatly enhanced if photocatalysis technique joint with Fenton process were employed in one system.

Differentiate with the sole $\mathrm{Fe}_{2} \mathrm{O}_{3}$ nanoparticles, Guo et al. (2019) constructed a Z-scheme hetero-structured $\alpha-\mathrm{Fe}_{2} \mathrm{O}_{3} @ g$ $\mathrm{C}_{3} \mathrm{~N}_{4}$ catalyst, which was obtained by calcination of melamine and Fe-based MOF. Commonly, MOFs are mainly used to prepare metal oxide nanoparticles, which can inherit the merits of metal oxide acting as sacrifice templates. The morphology characterization has been shown in Figure 5A. Regarding the TC degradation efficiency, by adjusting the addition amount of MIL$53(\mathrm{Fe})$, the researchers obtained the optimized composite, which exhibited excellent photo-Fenton performance for the removal of TC (Figure 5B). The corresponding degradation kinetic rate was calculated in Figure 5C, the $k$-value of FOCN-0.45 (0.042 $\min ^{-1}$ ) was 6,7 , and 14 times, compared to that of pristine MIL$53(\mathrm{Fe})\left(k=0.007 \mathrm{~min}^{-1}\right), \alpha-\mathrm{Fe}_{2} \mathrm{O}_{3}\left(k=0.006 \mathrm{~min}^{-1}\right)$, and g- $\mathrm{C}_{3} \mathrm{~N}_{4}\left(k=0.003 \mathrm{~min}^{-1}\right)$, respectively. As to reactive species, the scavenger results in Figure 5D demonstrated that $\cdot \mathrm{OH}$ was the dominant species, accompanied with $\mathrm{O}_{2}^{--}$and $\mathrm{h}^{+}$coparticipating in the degradation of TC. The specific mechanism of photo-Fenton reaction over Z-scheme hetero-structured $\alpha$ $\mathrm{Fe}_{2} \mathrm{O}_{3} @ g-\mathrm{C}_{3} \mathrm{~N}_{4}$ was shown in Figure 5E. Generally, g- $\mathrm{C}_{3} \mathrm{~N}_{4}$ and $\alpha-\mathrm{Fe}_{2} \mathrm{O}_{3}$ can be both excited under visible light $(420 \mathrm{~nm})$ irradiation to produce photo-induced electron $(\mathrm{e}-$ ) and hole $(\mathrm{h}+)$. Owing to the $\mathrm{Z}$-scheme structure, a proportion of electrons of the $\mathrm{CB}$ of $\alpha-\mathrm{Fe}_{2} \mathrm{O}_{3}$ would be prone to transferring to the $\mathrm{VB}$ of $g-\mathrm{C}_{3} \mathrm{~N}_{4}$. The electron of $\mathrm{CB}$ for $\mathrm{g}-\mathrm{C}_{3} \mathrm{~N}_{4}$ would react with $\mathrm{O}_{2}$ to produce superoxide radicals to degrade pollutants. Because of the $\mathrm{CB}$ position of $\alpha-\mathrm{Fe}_{2} \mathrm{O}_{3}$ more negative than the standard potential of $\mathrm{Fe}^{3+} / \mathrm{Fe}^{2+}(0.77 \mathrm{~V}$ vs. NHE), thus the electrons of $\alpha-\mathrm{Fe}_{2} \mathrm{O}_{3}$ were able to participate in the cycling of $\mathrm{Fe}^{3+} / \mathrm{Fe}^{2+}$, leading to activating $\mathrm{H}_{2} \mathrm{O}_{2}$ to generate hydroxyl radical. As to the holes in the VB of $\alpha-\mathrm{Fe}_{2} \mathrm{O}_{3}$, the VB position of $\alpha-\mathrm{Fe}_{2} \mathrm{O}_{3}$ $\left(1.98 \mathrm{~V}\right.$ vs. NHE) was lower than the potential of $\mathrm{OH}^{-} / \cdot \mathrm{OH}$ (1.99 V vs. NHE). Consequently, the accumulated holes in the VB of $\alpha-\mathrm{Fe}_{2} \mathrm{O}_{3}$ directly degraded the organic pollutants.

Furthermore, some other novel g- $\mathrm{C}_{3} \mathrm{~N}_{4}$ based nanomaterials have been progressed in photo-Fenton application. For instance, Palanivel et al. (2019) rationally designed an effective heterostructure $\left(\mathrm{ZnFe}_{2} \mathrm{O}_{4} / \mathrm{g}-\mathrm{C}_{3} \mathrm{~N}_{4}\right)$ nanocomposite, which showed good photo-Fenton performance for degradation of $20 \mathrm{mg} / \mathrm{L} \mathrm{MB}$. Besides $\mathrm{Fe}_{2} \mathrm{O}_{3}$ nanoparticles, Sahar et al. (2017) prepared $\mathrm{Fe}_{3} \mathrm{O}_{4} / g-\mathrm{C}_{3} \mathrm{~N}_{4}$ nanoparticles mainly throughout electrostatic self-assembly effect, exhibiting an obviously enhanced Fenton, photo-Fenton and peroxidase-like efficiency. To achieve the goal of easy access of recycling, Wang $\mathrm{H}$. et al. (2017) synthesized magnetic $\mathrm{BaFe}_{12} \mathrm{O}_{19} / \mathrm{g}$ $\mathrm{C}_{3} \mathrm{~N}_{4}$ nanocomposites, which showed excellent capacity and recyclability for removing $\mathrm{RhB}$. The enhanced photocatalytic performance was mainly attributed to the synergy of $\mathrm{BaFe}_{12} \mathrm{O}_{19}$ 


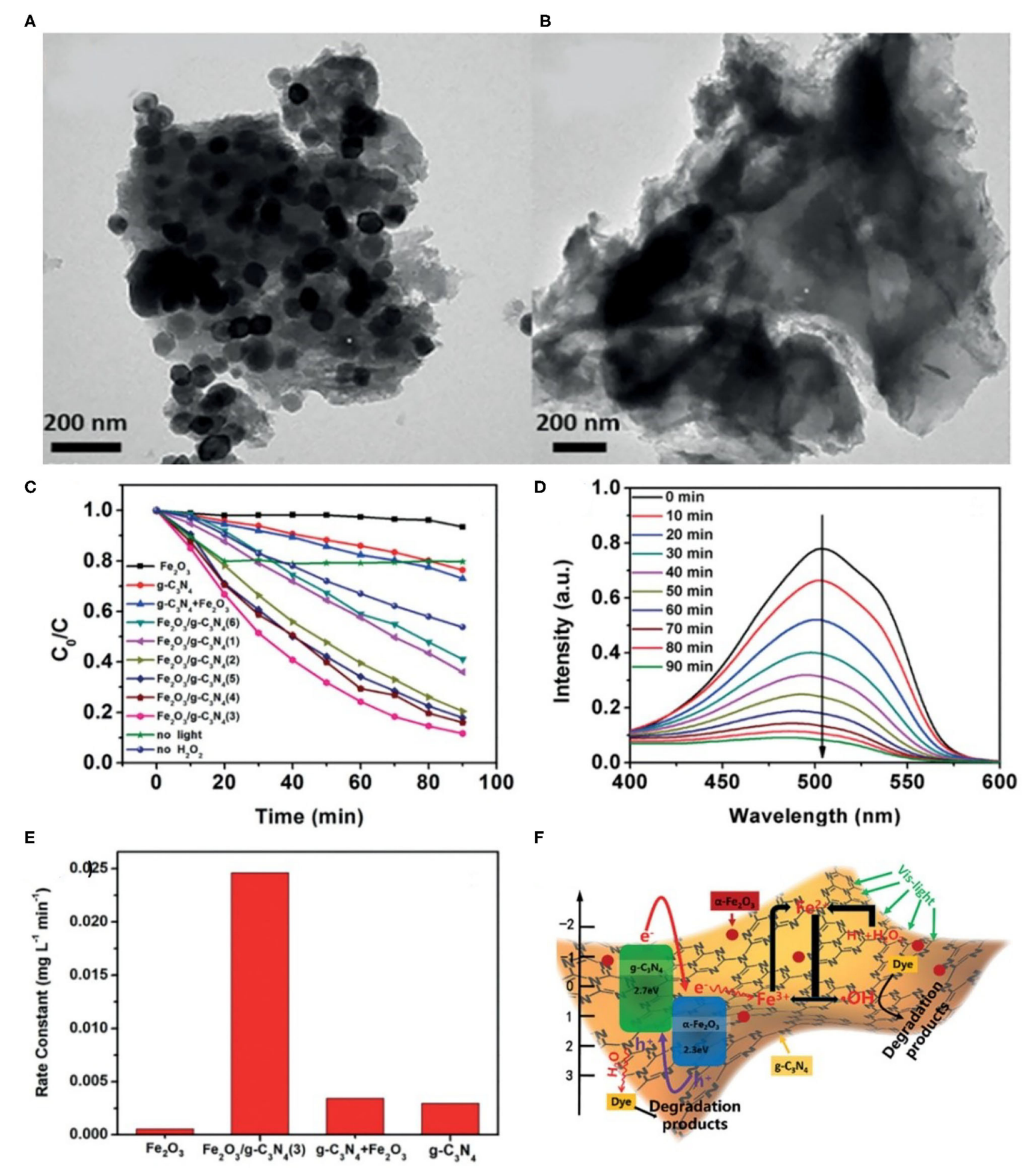

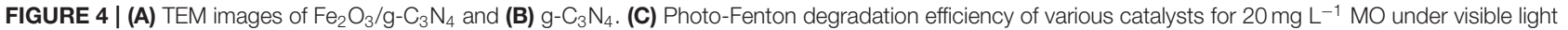
irradiation. (D) UVNis spectra of $\mathrm{MO}$ of $\mathrm{Fe}_{2} \mathrm{O}_{3} / \mathrm{g}-\mathrm{C}_{3} \mathrm{~N}_{4}$ at different time intervals. (E) Corresponding rate constant of various catalysts. (F) Proposed mechanism in the photo-Fenton reaction. Copied with permission (Zhou L. et al., 2016). Copyright 2016, Wiley. 
A
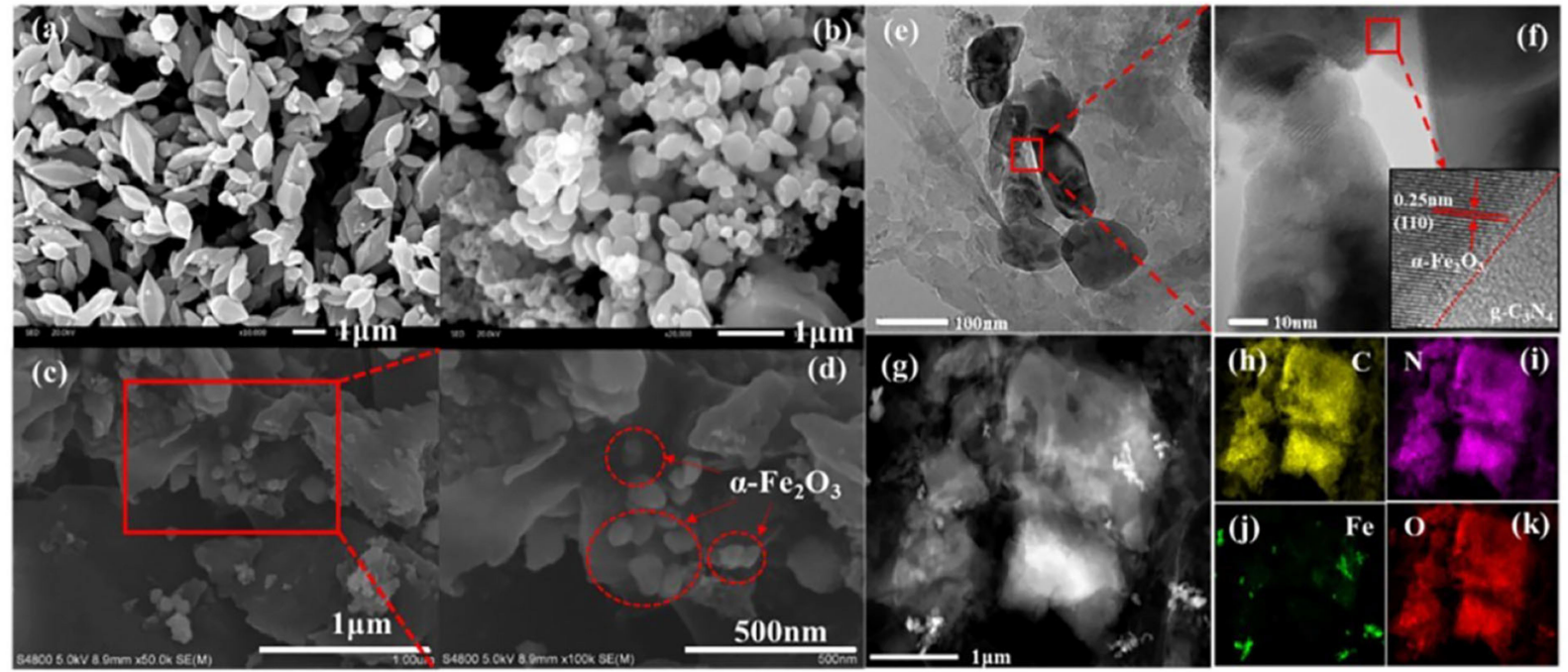

(c)

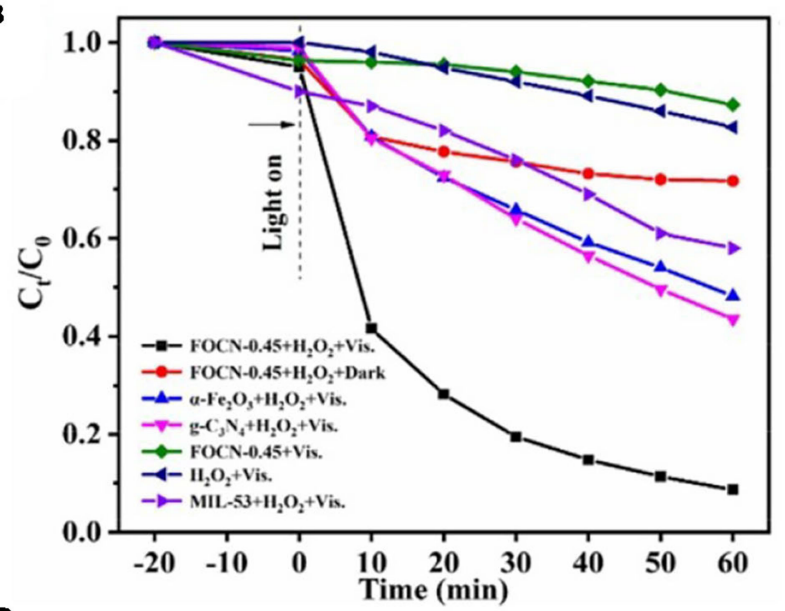

D

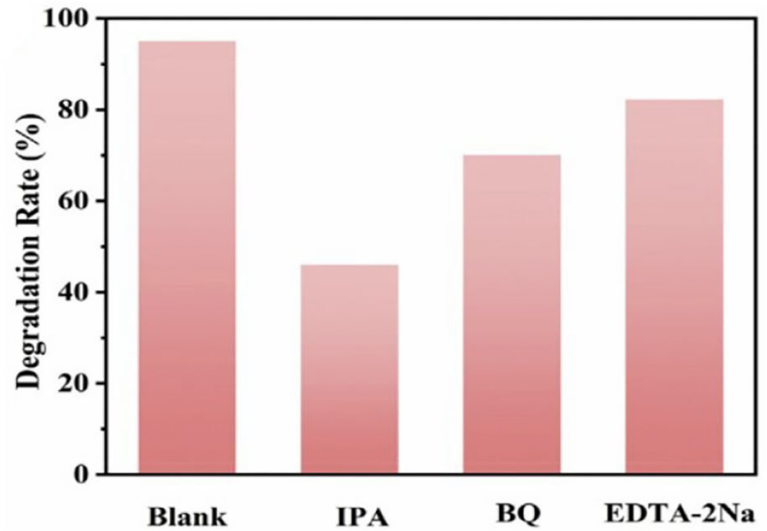

C

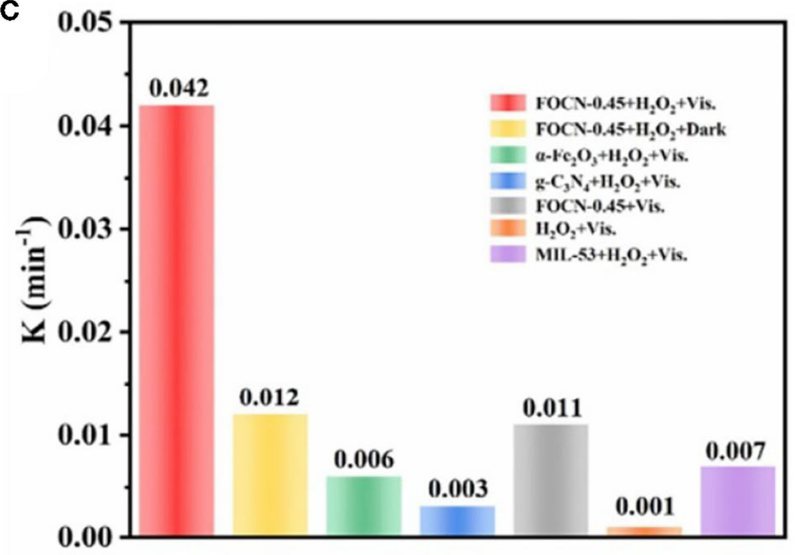

Samples

E

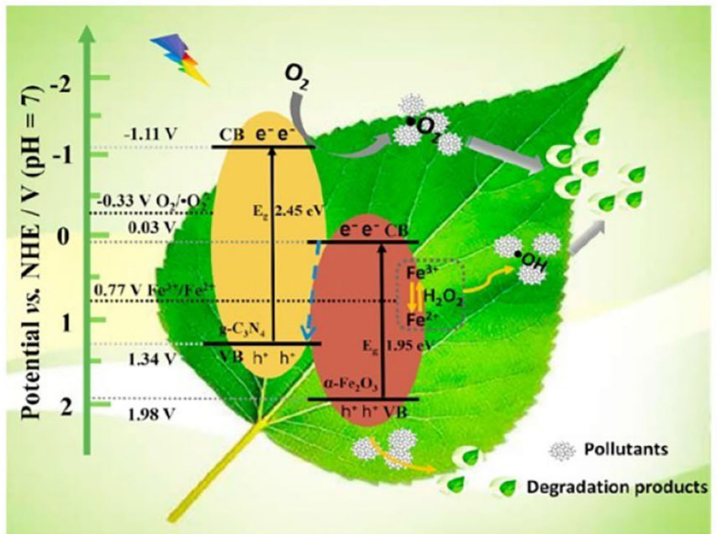

FIGURE 5 | (A) SEM images of MIL-53 (Fe) (a), $\alpha-\mathrm{Fe}_{2} \mathrm{O}_{3}$ (b), (c) FESEM image of FOCN-0.45 and its amplified area (d); (e) TEM and HRTEM (f) images of FOCN-0.45, (g) HAADF-STEM image; ( $h-k$ ) corresponding EDX mapping of FOCN-0.45. (B) TC degradation efficiency of different samples. (C) Kinetic calculation of various samples at different conditions. (D) Scavenger test of FOCN-0.45 for removing TC. (E) Photo-Fenton reaction mechanism illustration of $\alpha-\mathrm{Fe}_{2} \mathrm{O}_{3} @ \mathrm{~g}-\mathrm{C}_{3} \mathrm{~N}_{4}$ heterojunction. Copied with permission (Palanivel et al., 2019). Copyright 2019, Elsevier. 
TABLE 2 | Summary of $\mathrm{C}_{3} \mathrm{~N}_{4}$ based heterogeneous photo-Fenton like process under visible light irradiation.

\begin{tabular}{|c|c|c|c|c|c|c|c|}
\hline Catalyst & Target pollutant & $\mathrm{pH}$ & Catalyst dose & $\begin{array}{l}\mathrm{H}_{2} \mathrm{O}_{2} \\
\text { dose }\end{array}$ & $\begin{array}{l}\text { Reaction } \\
\text { time }\end{array}$ & Decolorization & References \\
\hline $\mathrm{g}-\mathrm{C}_{3} \mathrm{~N}_{4} / \mathrm{FeOCl}$ & $\begin{array}{l}50 \mathrm{mg} / \mathrm{L} \text { tetracycline } \\
10 \mathrm{mg} / \mathrm{L} \text { rhodamine B }\end{array}$ & / & $\begin{array}{l}0.2 \mathrm{~g} / \mathrm{L} \\
0.2 \mathrm{~g} / \mathrm{L}\end{array}$ & $2 \mathrm{mM}$ & $60 \min$ & $90 \%$ & Zhao et al., 2020 \\
\hline $\mathrm{g}-\mathrm{C}_{3} \mathrm{~N}_{4}-\mathrm{IMD}-\mathrm{FePcCl}_{16}$ & Carbamazepine (CBZ) & 7.0 & $0.1 \mathrm{~g} / \mathrm{L}$ & $5 \mathrm{mM}$ & $100 \mathrm{~min}$ & $100 \%$ & Chen X. et al., 2017 \\
\hline $\mathrm{g}-\mathrm{C}_{3} \mathrm{~N}_{4} / \mathrm{LaFeO}_{3}$ & 10 mg/L rhodamine B & / & $0.5 \mathrm{~g} / \mathrm{L}$ & $5 \mathrm{mM}$ & $120 \mathrm{~min}$ & $100 \%$ & Ye et al., 2018 \\
\hline Fe-doped g- $\mathrm{C}_{3} \mathrm{~N}_{4}$ & $\begin{array}{l}20 \text { mg/L phenol, bisphenol } \\
\text { A, 2, 4dichlorophenol }\end{array}$ & / & $1.0 \mathrm{~g} / \mathrm{L}$ & $8.0 \mathrm{mM}$ & $50 \min$ & $100 \%$ & Hu et al., 2019 \\
\hline $\begin{array}{l}\text { Oxygen doping } \mathrm{C}_{3} \mathrm{~N}_{4} \\
\left(\mathrm{HS} \text { g- } \mathrm{C}_{3} \mathrm{~N}_{4}-\mathrm{O}\right)\end{array}$ & Rhodamine B & / & $\begin{array}{l}0.5 \mathrm{mg} \mathrm{cat} \\
1.0 \mathrm{mM} \mathrm{FeCl}_{3}\end{array}$ & $20 \mathrm{mM}$ & $50 \mathrm{~min}$ & $100 \%$ & Guo et al., 2016 \\
\hline $\mathrm{Cu}_{2}(\mathrm{OH}) \mathrm{PO}_{4} / \mathrm{g}-\mathrm{C}_{3} \mathrm{~N}_{4}$ & $10 \mathrm{mg} \mathrm{L}^{-1} \mathrm{RhB}$ & / & $0.02 \mathrm{~g}$ cat & $10 \mathrm{mM}$ & $40 \mathrm{~min}$ & $100 \%$ & Chen et al., 2015 \\
\hline $\mathrm{Zn}_{1-1.5 x} \mathrm{Fe}_{\mathrm{x}} \mathrm{S} / \mathrm{g}-\mathrm{C}_{3} \mathrm{~N}_{4}$ & $\begin{array}{l}10 \text { mg/L p-nitrophenol } \\
\text { (PNP) }\end{array}$ & / & $0.8 \mathrm{~g} / \mathrm{L}$ & $1 \mathrm{mM}$ & $60 \min$ & $96 \%$ & Wang et al., 2020 \\
\hline $\mathrm{Fe}-\mathrm{g}-\mathrm{C}_{3} \mathrm{~N}_{4} / \mathrm{GMC}$ & 50 mg/L Acid Red 73 & / & $0.8 \mathrm{~g} / \mathrm{L}$ & $40 \mathrm{mM}$ & $40 \mathrm{~min}$ & $99.2 \%$ & Ma et al., 2017 \\
\hline
\end{tabular}

and $\mathrm{g}-\mathrm{C}_{3} \mathrm{~N}_{4}$, thus facilitating charge separation, and thereby promoted the photo-Fenton efficiency. For more examples, we have specially summarized many other excellent g- $\mathrm{C}_{3} \mathrm{~N}_{4}$ based nanomaterials in Table 2.

\section{Volatile Organic Compounds (VOCs) Removal}

Apart from the liquid-phase Fenton reaction, Li et al. (2016) constructed a solid-gas interfacial Fenton system, which is joint with an alkalized g- $\mathrm{C}_{3} \mathrm{~N}_{4}$ based photocatalyst, converting the photogenerated $\mathrm{H}_{2} \mathrm{O}_{2}$ into reactive oxygen species (ROS). This powerful case contains light acting as driving force, alkalized g- $\mathrm{C}_{3} \mathrm{~N}_{4}$-based photocatalyst as an in-situ $\mathrm{H}_{2} \mathrm{O}_{2}$ collector and surface-coated $\mathrm{Fe}^{3+}$ as a trigger for $\mathrm{H}_{2} \mathrm{O}_{2}$ conversion, thus achieving efficient activity of VOCs photodegradation. For instance, taking the photo-oxidation of isopropyl alcohol as a model. Specifically, Figure 6A showed the generation rate and apparent quantum yield (AQY) of acetone and $\mathrm{CO}_{2}$ at about $420 \mathrm{~nm}$ of each CNK-OH\&Fe catalyst with various $\mathrm{Fe}^{3+}$ loadings. Notably, the CNK-OH\&Fe samples exhibited an increasing photocatalytic capacity accounting for the loading amount of $\mathrm{Fe}^{3+}$. Consequently, when the loading amount $1.4 \mathrm{wt} \%$, it exhibited the optimal efficiency, signifying the increasing amount of $\mathrm{Fe}^{3+}$ loading not only promoting the utilization rate of photoelectron as well as suppressing the light absorption of catalyst. The IPA photooxidation rate of the optimal CNK$\mathrm{OH} \& \mathrm{Fe}$ sample achieved ca. 270 folds higher than that of pristine $\mathrm{C}_{3} \mathrm{~N}_{4}$ (Figure 6B). In Figure 6C, the generating $\mathrm{H}_{2} \mathrm{O}_{2}$ was difficult to be observed over $\mathrm{CNK}-\mathrm{OH} \& \mathrm{Fe}$, attributing to the generated $\mathrm{H}_{2} \mathrm{O}_{2}$ quickly reacting with $\mathrm{Fe}^{2+}$ and the photoelectrons quickly reducing $\mathrm{Fe}^{3+}$ to form $\cdot \mathrm{OH}$ radicals. To confirm the truth of $\mathrm{H}_{2} \mathrm{O}_{2}$ converting into $\cdot \mathrm{OH}$ radicals over $\mathrm{CNK}-\mathrm{OH} \& \mathrm{Fe}$, EPR test were performed. It was found that apart from the direct $\cdot \mathrm{OH}$ formation of surface hydroxyl radicals inducing from holes, the $\mathrm{CNK}-\mathrm{OH} \& \mathrm{Fe}$ indeed triggered the $\mathrm{Fe}^{2+}$ and $\mathrm{H}_{2} \mathrm{O}_{2}$ converting into $\cdot \mathrm{OH}$. On one hand, the enhanced efficiency was arising from the conversion of electrons promoting the generation of reactive radicals (e.g., $\cdot \mathrm{OH}$ and $\cdot \mathrm{O}_{2}^{-}$radicals) via the solid-gas interfacial Fenton process. On the other hand, the hydroxyl and $\mathrm{Fe}^{3+}$ species determined the insitu protons production and $\mathrm{Fe}^{2+} / \mathrm{Fe}^{3+}$ formation. In Figure 6D, the amount of hydroxyl radicals over $\mathrm{CNK}-\mathrm{OH} \& \mathrm{Fe}$ was ca. 4.0 times than that of $\mathrm{CNK}-\mathrm{OH}$. Figure 6E elaborately illustrated the possible mechanism over CNK-OH\&Fe catalyzed isopropanol conversion. As to quantum yield, in Figure 6F, compared with the pristine $\mathrm{C}_{3} \mathrm{~N}_{4}$, more than two orders of magnitude of conversion rate were obtained, which is equivalent to AQY of $49 \%$ around $420 \mathrm{~nm}$. In addition, it is expected that this discovery is not only unique for $\mathrm{C}_{3} \mathrm{~N}_{4}$-based nanomaterials, but provide a useful guidance for other semiconductors which can be alkalized on surface (e.g., $\mathrm{WO}_{3}$ and $\mathrm{SrTiO}_{3}$ ) should also provide the same light-driven Fenton process. It is expected that this will open a low economic cost and facile way to employ solar energy to effectively eliminate gaseous organic pollutants.

\section{Photo-Fenton-Like Membranes for Wastewater Treatment}

Membrane separation, a potential water treatment technology that has caused global attention to energy shortages and environmental pollution crises. In the last few decades, a vast amount of polymer and inorganic membranes have been deeply developed. Particularly, reverse osmosis (RO), plays a pivotal role in the generation of high-standard purified water, and simultaneously removes a vast number of contaminants (e.g., total dissolved solids, pathogens and organic pollutants).

In membrane development history, the thin film composite (TFC) polyamide membranes, thin film nanocomposite (TFN) membranes, molecular layer-by-layer (mLBL) membranes and self-assembled artificial water channels, carbon nanotubes (CNTs), microporous metal-organic frameworks (MOFs), graphene, graphene oxide, and $\mathrm{MoS}_{2}$ incorporated membranes have been deeply developed and studied; however, to meet all the demands of high-quality membranes including high selectivity, evitable stability and anti-fouling capabilities as well as high permeation flux, is still a huge challenge (Yang et al., 2016, 2018; Tang et al., 2018).

Interestingly, carbonaceous materials are gradually recognized as promising candidates for designing highperformance membranes, including of $1 \mathrm{D}$ carbon nanotubes, 


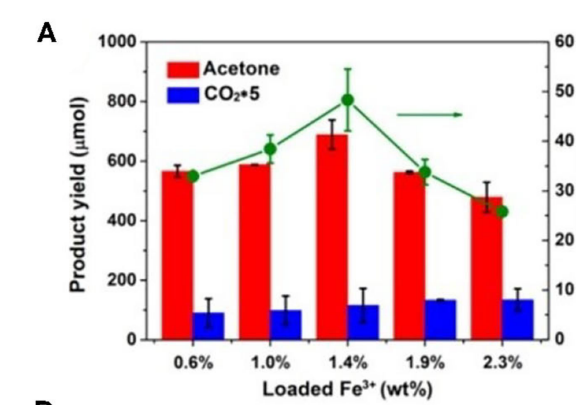

D

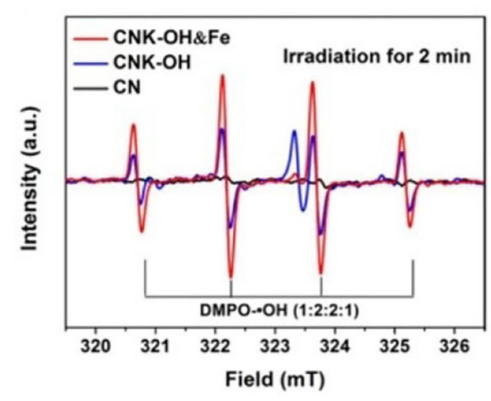

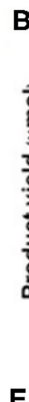

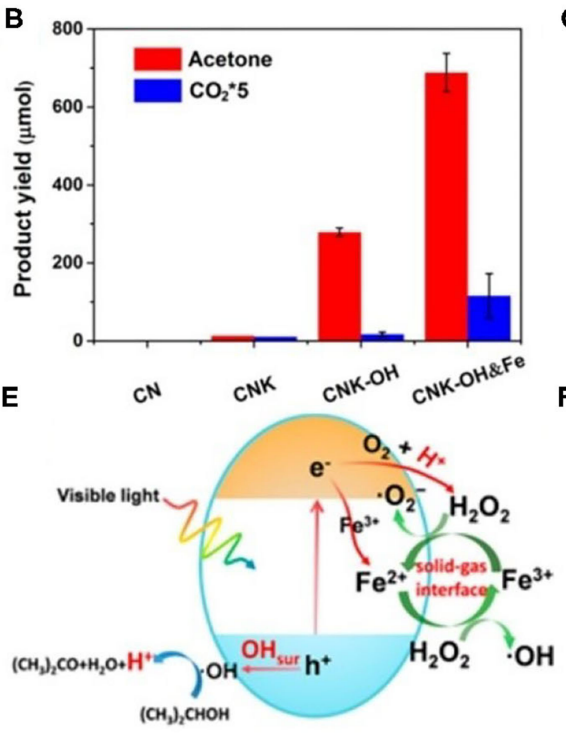

CNK-OH\&Fe
C

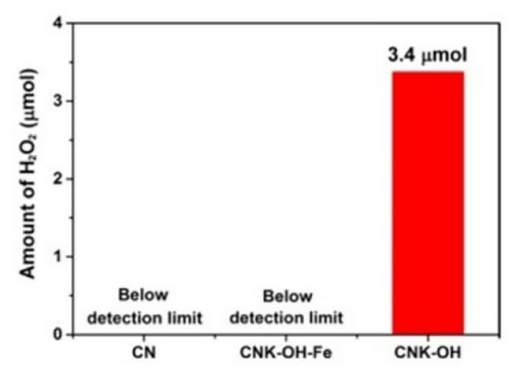

$\mathbf{F}$

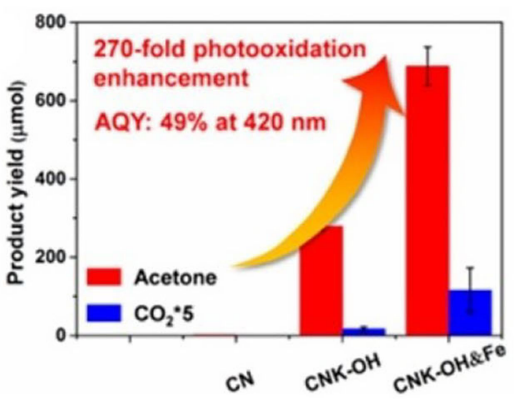

FIGURE 6 | (A) Product yield and AQY of CNK-OH\&Fe as a function of Fe ${ }^{3+}$ loading. (B) Photooxidation efficiency of various $\mathrm{C}_{3} \mathrm{~N}_{4}$-based photocatalysts. (C) Yield of $\mathrm{H}_{2} \mathrm{O}_{2}$ production over $\mathrm{C}_{3} \mathrm{~N}_{4}$-based samples. (D) EPR spectra of DMPO-.OH of different samples. (E) Proposed mechanism of solid-gas interfacial Fenton reaction over CNK-OH\&Fe. (F) Photooxidation performance of various $\mathrm{C}_{3} \mathrm{~N}_{4}$-based photocatalysts. Copied with permission (Li et al., 2016). Copyright 2016, ACS.

2D graphene as well as its derivatives. However, for the practical application of carbon materials, it is limited by the difficulty of manufacturing densely arranged nanostructures. In addition, as to graphene-based membranes, it is necessary to greatly enhance the permeability and structural stability of the membrane. Therefore, it is of paramount importance to constructing membranes with feasible mass transfer resistance and water permeation flux. It is worth noting that graphite carbon nitride $\left(\mathrm{g}-\mathrm{C}_{3} \mathrm{~N}_{4}\right)$ is expected to establish a new platform for the development of innovative membranes with excellent separation and self-cleaning properties, especially ultra-thin g- $\mathrm{C}_{3} \mathrm{~N}_{4}$ nanosheets. On this condition, for the first time, Lan et al. (2019) innovatively manufactured g- $\mathrm{C}_{3} \mathrm{~N}_{4}$-based catalytic membrane by soft self-assembly method for water purification. This membrane is mainly based on the nanochannels in g$\mathrm{C}_{3} \mathrm{~N}_{4}$ nanosheets and heterogeneous catalysis engaging in $\mathrm{Fe}$-containing polyoxometalates. As shown in Figure $\mathbf{7 A}$, the synthetic method of photo-Fenton-like membrane has been briefly described. Continuous modification of large amounts of g- $\mathrm{C}_{3} \mathrm{~N}_{4}$ is beneficial to forming $\mathrm{g}-\mathrm{C}_{3} \mathrm{~N}_{4}$ sol (step II). Afterwards, customized g- $\mathrm{C}_{3} \mathrm{~N}_{4}$ sol molecules with abundant amino and hydroxyl functional groups, provide enough active sites for Fe-POM nucleation (step III). After that, the self-assembly of the dispersion is filtered through a polycarbonate filter membrane to perform a carbonitride-based membrane treatment (Step IV). As shown in Figures $7 \mathbf{B}-\mathbf{E}$, the performance of POM incorporated into a $\mathrm{g}-\mathrm{C}_{3} \mathrm{~N}_{4}$ membrane was evaluated by pumping wastewater into membrane. First, the effect of carbon nitride microstructure was studied. As shown in Figure 7B, MB molecules can be completely removed from the water by $g-\mathrm{C}_{3} \mathrm{~N}_{4}$ membrane. Compared with the melamine-derived membrane, the urea-derived sample showed much better removal efficiency. Moreover, the versatility of $\mathrm{Ug}-\mathrm{C}_{3} \mathrm{~N}_{4} / \mathrm{Fe}$-POMs membranes in water purification was tested by filtering various dye molecules, as shown in Figure 7C. The results indicated that the synthesized membranes are capable of intercepting methyl blue (MB), Congo red $(\mathrm{CR})$, methyl orange $(\mathrm{MO})$, and rhodamine $\mathrm{B}(\mathrm{RhB})$ is extremely effective. In Figure $7 \mathrm{D}$, the unique nanochannels in $\mathrm{Ug}-\mathrm{C}_{3} \mathrm{~N}_{4} / \mathrm{Fe}-\mathrm{POM}$ ensured that contaminant molecules are completely removed through each filtration process. Therefore, if coupled with light irradiation and $\mathrm{H}_{2} \mathrm{O}_{2}$, this membrane exhibited stable water flux and good repelling ability (Figure 7E). In addition, a possible mechanism was proposed in Figure 7F. It was revealed that periodic atomic vacancies and structural defects in tri-s-triazine are conducive to the nanopores on the surface of the $\mathrm{g}-\mathrm{C}_{3} \mathrm{~N}_{4}$ layer. It is convinced that the gap between layers of carbon nitride provided a shortcut to dyes molecular diffusion. The modification of Fe-POMs significantly improved the separation performance of carbon nitride. In actual sewage treatment, the membranes were verified by pumping actual textile wastewater (initial COD: $290 \mathrm{mg} \mathrm{L}^{-1}$ ) over U-g- $\mathrm{C}_{3} \mathrm{~N}_{4} / \mathrm{Fe}-\mathrm{POMs}$ membranes. Generally, the greater the amount of $\mathrm{Fe}-\mathrm{POM}$ in the membrane, the higher the rejection rate, and the smaller the permeation flux of water (Figure 7G). As can be seen from Figure $\mathbf{7 H}$ that the addition of Fe-POMs posed a significant impact on the COD removal performance. Therefore, the U-gC $\mathrm{N}_{4} / \mathrm{Fe}-\mathrm{POMs}$ membrane maintained the same COD rejection rate and permeable flux after five 
A

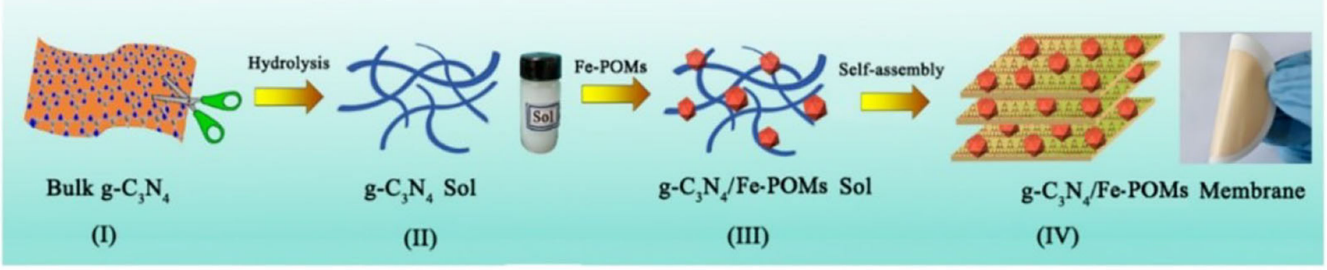

B

D
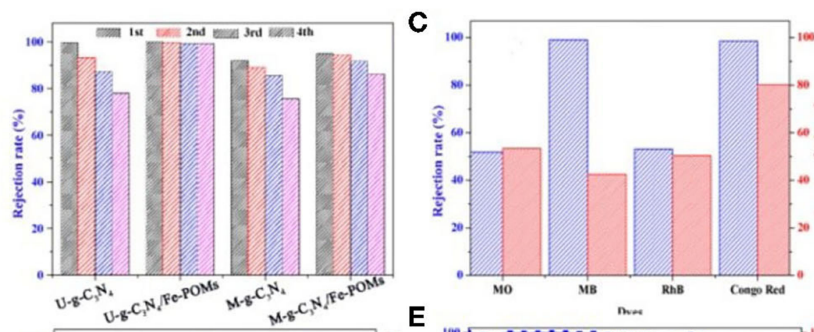

$\mathrm{E}$
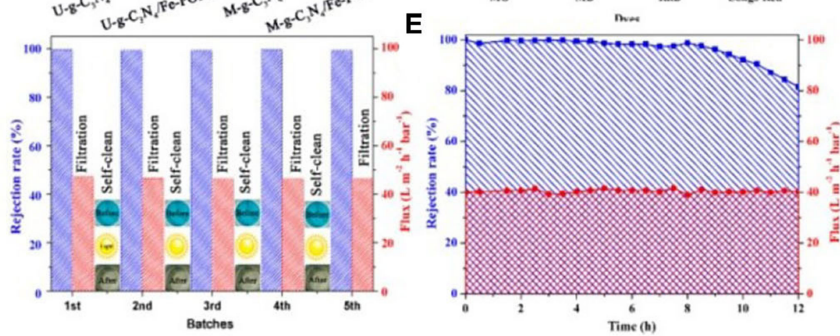
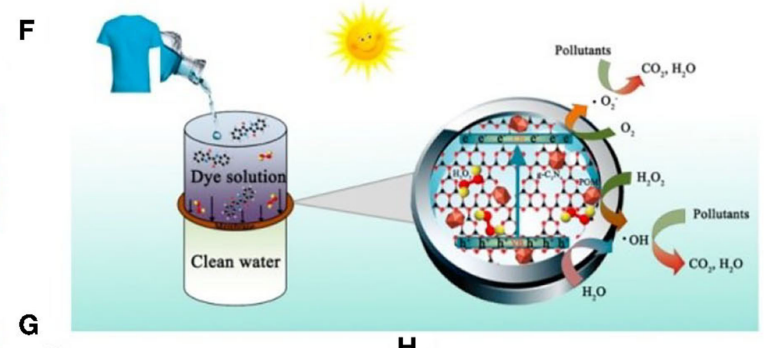

G
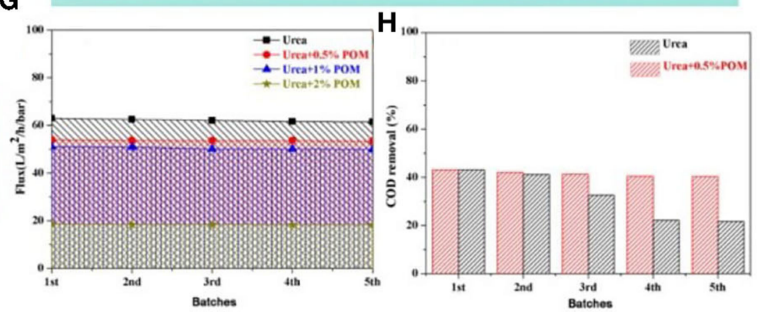

FIGURE 7 | (A) Schematic illustration of synthesis methodology of g- $\mathrm{C}_{3} \mathrm{~N}_{4} /$ Fe-POMs membranes. (B) Dye removal efficiency over different carbon-nitride-based membranes. (C) Filtration ability for $\mathrm{U}-\mathrm{g}-\mathrm{C}_{3} \mathrm{~N}_{4} / \mathrm{Fe}-\mathrm{POMs}$ membranes over various dye solutions. (D) Intermittent combination of membrane separation and photocatalytic oxidation process. (E) Treating MB solution by $\mathrm{U}-\mathrm{g}-\mathrm{C}_{3} \mathrm{~N}_{4} / \mathrm{Fe}-\mathrm{POMs}$ membranes with the aid of light and $\mathrm{H}_{2} \mathrm{O}_{2}$; (F) Possible mechanism of water purification over $\mathrm{U}$-g- $\mathrm{C}_{3} \mathrm{~N}_{4} / \mathrm{Fe}$-POMs membranes. (G) Influence of Fe-POMs content on the water permeation flux. (H) COD removal rate of $U$-g- $\mathrm{C}_{3} \mathrm{~N}_{4}$ and $\mathrm{U}-\mathrm{g}-\mathrm{C}_{3} \mathrm{~N}_{4} / 1 \%$ Fe-POMs membranes in batch filtration experiments. Copied with permission (Lan et al., 2019). Copyright 2019, ACS.

batches of treatment. It well reveals the merits of self-assembled photo-Fenton membrane based on Fe-POM. Overall, this work provides a viable way to develop catalytic carbonitride-based membranes for water purification.

In this section, graphite carbon nitride $\left(\mathrm{g}-\mathrm{C}_{3} \mathrm{~N}_{4}\right)$ nanomaterials were reviewed for the application of photoFenton process in removing organic pollutant, volatile organic compounds (VOCs) removal and membrane separation for wastewater. If irradiated by visible light or solar light, the photo-generated electrons facilitated the cycle of $\mathrm{Fe}^{3+} / \mathrm{Fe}^{2+}$, leading to the enhanced efficiency of organic pollutant and VOCs removal, which is attributed to the simultaneous photocatalytic effect as well as photo-Fenton oxidation process. According to this line of thought, $\mathrm{g}-\mathrm{C}_{3} \mathrm{~N}_{4}$ can be a promising candidate not only in organic pollutant removal but also assist in membrane separation and self-cleaning.

\section{REDUCED GRAPHENE OXIDE (RGO)-BASED PHOTOCATALYTIC FENTON REACTION}

Graphene has been recognized as an excellent candidate supporting material owing to its unique physical properties, such as a high electric potential density, electron mobility, and optical absorption (Nair et al., 2008; Mayorov et al., 2011). In the field of environmental remediation, for instance, graphene is usually employed as a good support for loading nanomaterials, such as $\mathrm{TiO}_{2}, \mathrm{ZnO}, \mathrm{Fe}_{2} \mathrm{O}_{3}, \mathrm{CdS}, \mathrm{Co}_{3} \mathrm{O}_{4}$, and CdSe, etc. (Xiang et al., 2012; Guo et al., 2013) With the assistance of graphene, these nanocomposites can be uniformly dispersed onto graphene nanosheets and suppress aggregation, thus enhancing the catalytic efficiency because of excellent specific area and electrical conductivity (Wang et al., 2016). In the broad sense of Fenton process, two-dimensional graphene nanosheets and three-dimensional graphene hydrogel or aerogel have been deeply investigated. In the last decade, graphene-based nanocomposites, such as $\mathrm{Fe}_{2} \mathrm{O}_{3}$ /graphene oxide and $\mathrm{Fe}_{3} \mathrm{O}_{4} / \mathrm{RGO}$ composites have been widely studied in removing organic pollutants (Xiang et al., 2012; Qiu et al., 2016b). These reported graphene-based photocatalysts show excellent photocatalytic activity, which is due to the transfer of photogenerated charge from the NPs surface to the graphene surface, thereby promoting the separation of electron-hole pairs and the generation of additional $\cdot \mathrm{OH}$ radicals. In addition, the combination of the aromatic ring of rGO and organic pollutants mainly comes into being $\pi-\pi$ interaction and electrostatic interaction, which is conducive to the degradation process (Zhang et al., 2009; Sun 
(A)

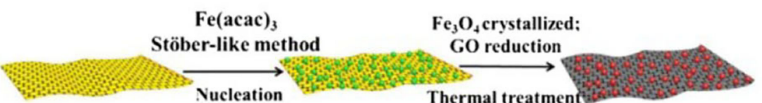

Graphene oxide (GO)

Amorphous $\mathrm{Fe}_{3} \mathrm{O}_{4} / \mathrm{GO}$

$\mathrm{Fe}_{3} \mathrm{O}_{4} / \mathrm{RGO}$

- Amorphous $\mathrm{Fe}_{3} \mathrm{O}_{4}$ nanoparticles - Crystalline $\mathrm{Fe}_{3} \mathrm{O}_{4}$ nanoparticles

(B)

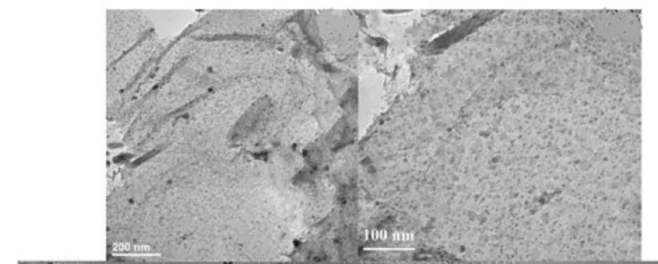

(C)

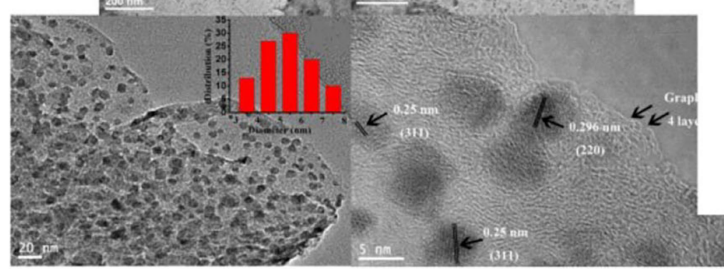

(D)

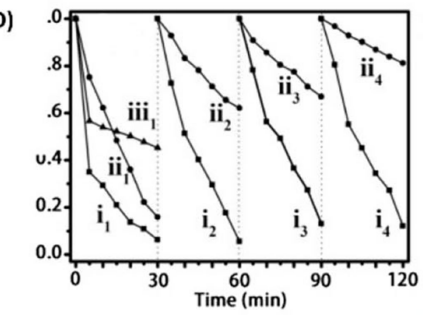

(F)
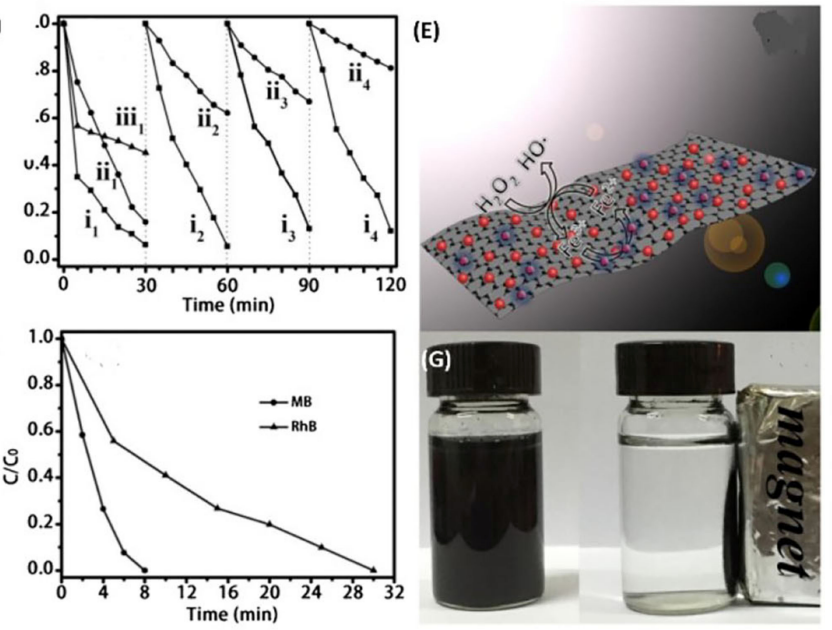

FIGURE 8 | (A) Synthetic route of $\mathrm{Fe}_{3} \mathrm{O}_{4} / \mathrm{RGO}$ nanomaterials; (B) TEM image and (C) HRTEM image of Fe $\mathrm{F}_{4} / \mathrm{RGO}$ nanomaterials (Inset: particle size distribution of the loaded $\mathrm{Fe}_{3} \mathrm{O}_{4}$ nanoparticles); (D) Cycling test of $\mathrm{Fe}_{3} \mathrm{O}_{4} / \mathrm{RGO}$ and commercial $\mathrm{Fe}_{3} \mathrm{O}_{4}$ for degradation of $\mathrm{MO}$ irradiated by solar light; (E) Possible proposed photo-Fenton process mechanism of $\mathrm{Fe}_{3} \mathrm{O}_{4} / \mathrm{RGO}$; (F) Photo-Fenton degradation of $10 \mathrm{mg} / \mathrm{L} \mathrm{MB}$ and $10 \mathrm{mg} / \mathrm{L} \mathrm{RhB;} \mathrm{(G)} \mathrm{Magnetic} \mathrm{recycle} \mathrm{of} \mathrm{Fe} \mathrm{O}_{4} / \mathrm{RGO}$ photocatalyst. Copied with permission (Qiu et al., 2016b). Copyright 2016, Elsevier.

et al., 2020). Especially, $\mathrm{Fe}_{2} \mathrm{O}_{3}, \mathrm{FeOOH}$, and $\mathrm{Fe}_{3} \mathrm{O}_{4}$ have been reported effective in Fenton reaction. Additionally, the threedimensional graphene-based hydrogels, as well as aerogels have been investigated a lot in photo-Fenton like reaction. In this section, we will clarify them gradually.

\section{Two-Dimensional Graphene-Based Nanomaterials}

In 2016, Wang et al. (2016) prepared $\mathrm{Fe}_{3} \mathrm{O}_{4} @ \mathrm{HG}$ with hydrophilic graphene (HG) and $\mathrm{Fe}_{3} \mathrm{O}_{4}$, which presented high removal efficiency of methyl orange (MO), owing to the rapid transference of photo-generated electrons on the surface of $\mathrm{HG}$ to promote the conversion efficiency of $\mathrm{Fe}^{3+} / \mathrm{Fe}^{2+}$. Further, Liu et al. (2017a) developed $\alpha-\mathrm{Fe}_{2} \mathrm{O}_{3}$ loaded graphene oxide (GO) nanosheets through a facile hydrolysis process, which showed good Fenton-degradation efficiency for $\mathrm{MB}$ as well as rhodamine B, Orange II and Orange G, phenol, 2nitrophenol and 17-estradiol (E2). An et al. (2013a) synthesized graphene- $\mathrm{BiFeO}_{3}$ composite for the photo-Fenton degradation of tetrabromobisphenol A. Moreover, Qiu et al. (2016b) innovatively adopted a Stöber-like method to synthesize ultradispersed $\mathrm{Fe}_{3} \mathrm{O}_{4}$ nanoparticles onto graphene, which was applied in photo-Fenton reaction and lithium-battery. As presented in Figure 8A, the in-situ grown $\mathrm{Fe}_{3} \mathrm{O}_{4}$ particles were uniformly dispersed on graphene layers via a Stöber-like method. The morphology and structure of the $\mathrm{Fe}_{3} \mathrm{O}_{4} / \mathrm{RGO}$ composites have been characterized by TEM and HRTEM, as shown in Figures 8B,C, respectively. TEM images showed that the thickness of the RGO plate with highly dispersed $\mathrm{Fe}_{3} \mathrm{O}_{4}$ nanoparticles is ultrathin (Figure 8B). The HRTEM image of the $\mathrm{Fe}_{3} \mathrm{O}_{4} / \mathrm{RGO}$ composite (Figure 8C) showed that all nanoparticles are well-dispersed on graphene, and the size distribution shows an average size of 3-8 nm. HRTEM images show clear crystal lattices with a pitch of 0.250 and $0.296 \mathrm{~nm}$, corresponding to the (311) and (220) planes, respectively. The photo-Fenton ability was conducted in the presence of $\mathrm{H}_{2} \mathrm{O}_{2}$ under the irradiation of solar light. Correspondingly, the result showed that the $\mathrm{Fe}_{3} \mathrm{O}_{4} / \mathrm{RGO}$ catalyst possessed superior photoFenton activity (98\%) (Figure 8D). The possible mechanism has been illustrated in Figure 8E. Once irradiated by solar light, these electrons generating from dyes and $\mathrm{Fe}_{3} \mathrm{O}_{4}$ NPs transferred to the graphene; meanwhile, $\mathrm{Fe}^{3+}$ ions can easily be reduced by photo-electrons back to $\mathrm{Fe}^{2+}$. Consequently, $\mathrm{Fe}^{2+}$ continue to react with $\mathrm{H}_{2} \mathrm{O}_{2}$ to produce more $\mathrm{OH}$ radicals on the surface of graphene (Figure 8E). As a result, the $\mathrm{Fe}_{3} \mathrm{O}_{4} / \mathrm{RGO}$ composites possessed an excellent photo-Fenton capacity for degradation of organic dyes (Figure 8F), which can be recycled by an extra magnetic (Figure 8G).

\section{Three-Dimensional Graphene-Based Hydrogel or Aerogel}

Besides the two-dimensional (2D) graphene-based heterogenous catalysts, to achieve the facile recycle of catalysts, threedimensional (3D) graphene hydrogel or aerogel has been developed by many researchers, such as cobalt ferrite nanoparticles related graphene aerogel (Qiu et al., 2016a), graphene oxide (GO)-carbon nanotubes (CNTs)-FeOOH aerogel (Liu et al., 2017b), stretchable $\mathrm{Fe}_{2} \mathrm{O}_{3}$ /graphene aerogels (Qiu 


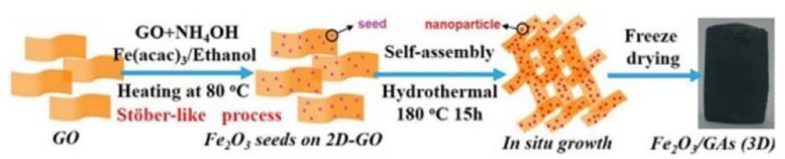

B

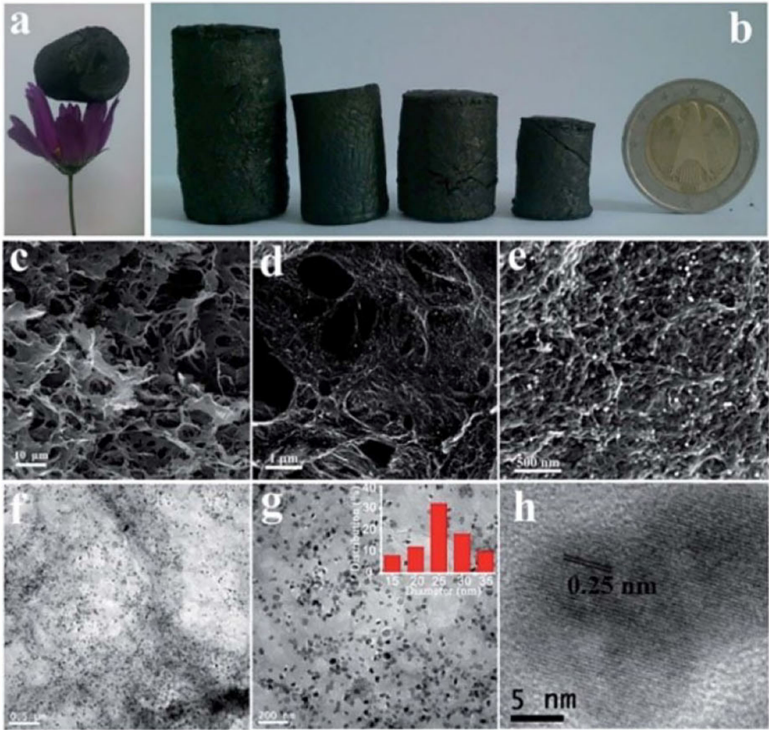

C
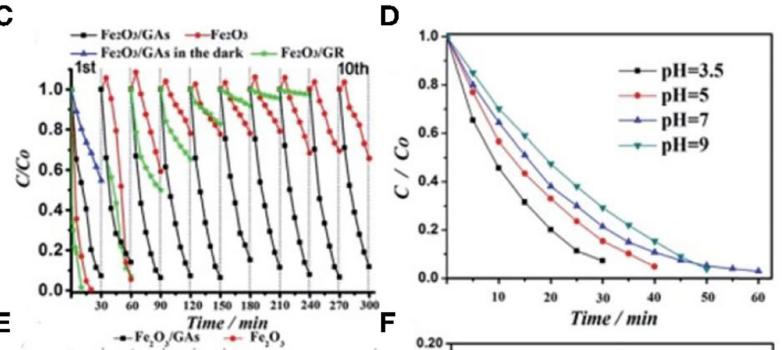

E

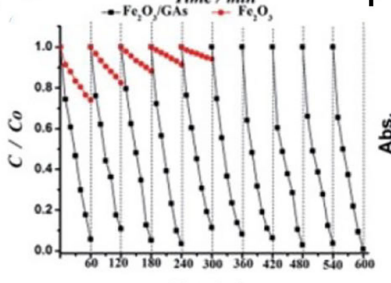

Time/min

G

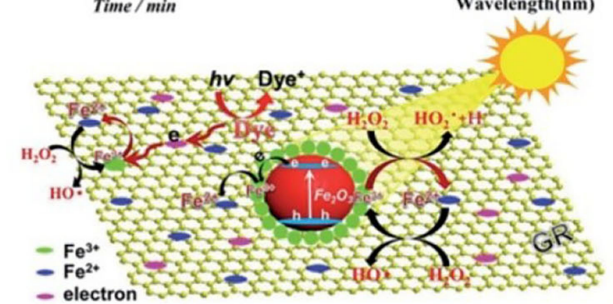

FIGURE 9 | (A) Illustration of synthesis methodology of $\mathrm{Fe}_{2} \mathrm{O}_{3} / \mathrm{Gas}$; (B) (a) photographs of as-prepared $\mathrm{Fe}_{2} \mathrm{O}_{3} / \mathrm{GAs}$; (b) images of $\mathrm{Fe}_{2} \mathrm{O}_{3} / \mathrm{GAs}$ prepared via different reaction volumes; (c) SEM and (d,e) FE-SEM image of $\mathrm{Fe}_{2} \mathrm{O}_{3} / \mathrm{GAs}(\mathrm{f}, \mathrm{g}) \mathrm{TEM}$, and (h) HR-TEM images of $\mathrm{Fe}_{2} \mathrm{O}_{3} / \mathrm{GAs}$; (C) cycling test for the photo-Fenton degradation of MO; (D) photo-Fenton degradation of $\mathrm{MO}$ by $\mathrm{Fe}_{2} \mathrm{O}_{3} / \mathrm{Gas}$; (E) cycle test for the photo-Fenton degradation of $\mathrm{MO}$ on different catalysts $(\mathbf{F}) \mathrm{Fe}^{2+}$ detection of $\mathrm{Fe}_{2} \mathrm{O}_{3}$ powders and $\mathrm{Fe}_{2} \mathrm{O}_{3} / \mathrm{GAs}$ in the presence of 1,10-phenanthroline; (G) Photo-Fenton reaction model of $\mathrm{Fe}_{2} \mathrm{O}_{3} / \mathrm{GAs}$. Copied with permission (Qiu et al., 2015). Copyright 2015, RSC.

et al., 2015), reduced graphene oxide nanosheet/FexOy/nitrogendoped carbon layer aerogel (Yao et al., 2019), $\mathrm{Fe}_{3} \mathrm{O}_{4} / \mathrm{RGO} / \mathrm{PAM}$ hydrogel (Dong et al., 2018c), etc.

Among these 3D graphene-based materials, especially, the graphene oxide aerogels have attracted tremendous attention in recent years, which is a new category of porous $3 \mathrm{D}$ framework, owing to its large surface-to-volume ratio, good electron mobility and conductivity, superior mechanical stability, and good adsorption capacity (Leary and Westwood, 2011). In a broad sense, 2D layered structures equipped with $\mathrm{sp}^{2}$ and $\mathrm{sp}^{3}$-hybridized carbon atoms are assembled in hexagonal rings, making graphene a useful building block for matrix selfassembly, whereas graphene aerogel can be effectively prevent graphene sheets from stacking. Generally, doping a metal oxide into porous $3 \mathrm{D}$ structure can effectively suppress stacking; meanwhile, these $3 \mathrm{D}$ aerogels possess huge surface area, fast mass and electron transfer kinetics, short diffusion paths in the matrix and good mechanical strength (Sui et al., 2012).

In addition, some previous studies have reported that nanoscale iron oxide in graphene aerogels, which possessed few defects, are especially effective for photo-Fenton degradation of phenols and more complex benzene ring compounds. For example, Qiu et al. (2015) reported three-dimensional (3D) $\mathrm{Fe}_{2} \mathrm{O}_{3}$ in-situ grown on graphene aerogels via Stöber-like method, as shown in Figure 9A. The obtained $\mathrm{Fe}_{2} \mathrm{O}_{3} / \mathrm{GAs}$ exhibited a 3D macroscopic appearance (Figure 9B, inset a) and an ultralight materials property. With the reaction volume increasing, the obtained $\mathrm{Fe}_{2} \mathrm{O}_{3} / \mathrm{GAs}$ increase in size (Figure $\mathbf{9 B}$, inset b). The SEM image of $\mathrm{Fe}_{2} \mathrm{O}_{3} / \mathrm{GAs}$ indicated that the $\mathrm{Fe}_{2} \mathrm{O}_{3} / \mathrm{GAs}$ possessed a 3D macroporous structure (Figure 9B, inset $\mathrm{c}, \mathrm{d}$ ). $\mathrm{Fe}_{2} \mathrm{O}_{3}$ nanocrystals are well-embedded into graphene sheets (Figure 9B, inset e). TEM results further confirmed the highly dispersed $\mathrm{Fe}_{2} \mathrm{O}_{3}$ nanocrystals on the surface of graphene (Figure 9B, inset f,g). HRTEM image of $\mathrm{Fe}_{2} \mathrm{O}_{3} / \mathrm{GAs}$ revealed that d-spacing lattice fringes is ca. $0.25 \mathrm{~nm}$, which corresponded to the (110) planes of $\mathrm{Fe}_{2} \mathrm{O}_{3}$ (Figure 9B, inset h). Subsequently, $\mathrm{Fe}_{2} \mathrm{O}_{3} / \mathrm{GAs}$ was investigated for the solar-light-driven Fenton reaction the in the presence of $\mathrm{H}_{2} \mathrm{O}_{2}$ for the degradation of $10 \mathrm{mg} / \mathrm{L} \mathrm{MO}$ solution (Figures 9C-E). The highly photoFenton reaction activity was mainly caused by the conversion of $\mathrm{Fe}^{3+} / \mathrm{Fe}^{2+}$ instead of the adsorption. Unlike $\mathrm{Fe}_{2} \mathrm{O}_{3} / \mathrm{GR}$, the $3 \mathrm{D}-\mathrm{GAs}$ can prevent the $\mathrm{Fe}^{2+}$ from dissolving in the solution owing to its channels and confinement effect. Besides the acidic conditions, the $\mathrm{pH}$ value can be adapted to neutral condition at 7.0, and the corresponding Fenton efficiency of $\mathrm{Fe}_{2} \mathrm{O}_{3} / \mathrm{GAs}$ still keeps at a high level, which is much higher than pristine $\mathrm{Fe}_{2} \mathrm{O}_{3}$ (Figures 9D,E). It is well-known that $\mathrm{Fe}^{3+} / \mathrm{Fe}^{2+}$ cycle plays a crucial role in Fenton reaction. The excessive $\mathrm{Fe}^{3+}$ ions easily produce iron sludge in the aqueous solution, thus deactivating and poisoning the catalyst. In Fenton process, $\mathrm{Fe}^{3+}$ ions can 
capture the photo-induced electrons and be reduced to $\mathrm{Fe}^{2+}$, thus a high concentration of $\mathrm{Fe}^{2+}$ ions, which is complexed with phenanthroline can be detected in the solution (Figure 9F). The three-dimensional frame can effectively prevent the dissolution of iron. Once irradiated by solar light, the electrons can be both excited from dyes and $\mathrm{Fe}_{2} \mathrm{O}_{3}$ nanocrystals, which will transfer to the graphene (Figure 9G), leading to positive ions (e.g., $\mathrm{Fe}^{2+}$ and $\mathrm{Fe}^{3+}$ ) adsorbed onto the negative-charge graphene. These $\mathrm{Fe}^{3+}$ ions will subsequently capture photo-induced electrons and react with $\mathrm{H}_{2} \mathrm{O}_{2}$ to produce $\mathrm{Fe}^{2+}$ ions again.

Additionally, Liu et al. (2018) used non-toxic sodium ascorbate as reductant to synthesize $\mathrm{FeO}(\mathrm{OH})$ /reduced graphene oxide aerogel $(\mathrm{FeO}(\mathrm{OH})$-rGA) by means of facile and greenchemistry approach. The stable anchorage can ensure the circulation rate and reduce the leaching of iron, thereby ensuring the effective degradation of toxic phenolic compounds under visible light irradiation. Overall, the aerogel obtained not only has a stable structure, but also has significant catalytic activity for the degradation of phenolic organics at neutral pH. Besides this, Dong et al. (2018c) also developed a functional graphene hydrogel equipped with simultaneous photocatalytic Fenton reaction activity for the degradation of organic pollutants and adsorption for the heavy metal ions. These above-mentioned $3 \mathrm{D}$ graphene-based hydrogels or aerogels provide researchers a new pathway to process the wastewater treatment.

In a summary, reduced graphene oxide (RGO) based nanomaterials have been extensively employed in photocatalytic Fenton reaction, varying from two-dimensional (2D) nanosheets to three-dimensional (3D) hydrogels or aerogels. Especially, the $2 \mathrm{D}$ graphene nanosheets blocked the aggregation of iron oxide nanoparticles, benefiting the electron transferring on graphene and impeding the generation of iron sludge during photoFenton process. As to $3 \mathrm{D}$ graphene hydrogels and aerogels, it can effectively prevent the stacking of $2 \mathrm{D}$ graphene nanosheets by doping of metal ions. Moreover, its 3D-structured shape is suitable for multiple and simple recycling. It is expected that reduced graphene oxide will build a new platform for environmental remediation.

\section{OTHER SEMICONDUCTORS-BASED PHOTOCATALYTIC FENTON REACTION}

Except of the $\mathrm{TiO}_{2}$-based, graphitic carbon nitride-based and graphene-based nanomaterials, some other semiconductor-based nanomaterials can work as effectively as well in photo-Fenton process, such as Ag (Chen et al., 2016; Zhu et al., 2018a,b), $\mathrm{BiVO}_{4}$ (Xu et al., 2017; Li X. et al., 2018; Gao et al., 2019), ZnO (Choi et al., 2015; Ojha et al., 2017; Saleh and Taufik, 2019), $\mathrm{ZnFeO}_{4}$ (Khadgi and Upreti, 2019; Palanivel et al., 2019), and $\mathrm{BiFeO}_{3}$ (Luo et al., 2010; An et al., 2013b; Jia et al., 2018), etc. In this section, we will make a brief description, including of Ag-based nanomaterials, $\mathrm{BiVO}_{4}$-based nanomaterials, $\mathrm{ZnFeO}_{4}$ and $\mathrm{BiFeO}_{3}$ based nanomaterials, which all perform well as photo-Fenton like catalysts.

\section{Ag-Based Photo-Fenton Catalysts}

In the past few decades, people have paid great attention to the research on the heterogeneous photo-Fenton process for the degradation of organic pollutants. As far as known, the high combination rate of photo-generated carriers will impede its photocatalytic efficiency. Thus, an idea is proposed that the joint of photo-Fenton catalysts with plasmonic materials, this issue might be solved.

Some researchers have reported that $\mathrm{Ag} / \mathrm{AgCl} / \mathrm{Fe}-\mathrm{S}$ plasmonic catalyst could effectively degrade bisphenol $\mathrm{A}$ in photo-Fenton system under visible light irradiation (Liu et al., 2017c). Further, Zhu et al. (2018b) reported that a novel photo-Fenton catalyst of $\mathrm{Ag} / \mathrm{AgCl} /$ ferrihydrite could degrade bisphenol A as well, which revealed that the loading of $\mathrm{Ag} / \mathrm{AgCl}$ could accelerate the conversion of $\mathrm{Fe}^{3+} / \mathrm{Fe}^{2+}$ by the photo-generated electrons transferring from $\mathrm{Ag}$ nanoparticles owning to the surface plasmon resonance (SPR) effect. Moreover, Chen et al. (2016) prepared Ag/hematite mesocrystal, which displayed a high photo-Fenton activity in the oxidation of $\mathrm{RhB}, \mathrm{MO}$ and glyphosate under visible light irradiation.

\section{$\mathrm{BiVO}_{4}$-Based Photo-Fenton Catalysts}

In recent years, $\mathrm{BiVO}_{4}$ has been well-considered as a typical photocatalyst with narrow band gap. Due to its non-toxicity, good stability and photochemical properties, it has been extensively studied in the treatment of photocatalytic wastewater. In addition, $\mathrm{BiVO}_{4}$ is a good candidate cocatalyst in photoFenton process; however, pure $\mathrm{BiVO}_{4}$ is constrained by several drawbacks, such as a narrow visible light response range, low specific surface area, and rapid recombination of charged charges. Thus, various modification strategies have been adopted to investigate its potential application including doping ions, heterostructure fabrication, and precious metal deposition.

Specifically, Liu et al. (2017c) synthesized Fe(III) grafted $\mathrm{BiVO}_{4}$ nanosheets, which was employed for the photodegradation of 2,4-dichlorophenol and antibiotics. The results showed that the $\mathrm{Fe}^{3+}$ species not only served as efficient electron scavengers, but also provided more active reaction sites. The detailed mechanism is briefly contained in Figure 10A. In Figure 10B, pure $\mathrm{BiVO}_{4}$ merely could degrade ca. $60 \%$ of TC under visible-light irradiation. When the mass content of $\mathrm{Fe}$ (III) was $7 \%$, the degradation efficiency can be up to $80 \%$. Correspondingly, in Figure 10C, the TOC removal efficiency for $7 \% \mathrm{Fe}(\mathrm{III})-\mathrm{BVO}$ could be up to $48 \%$ after $60 \mathrm{~min}$. Moreover, quinolones antibiotics, including CIP, GAT, and LVX were selected to be degraded. As shown in Figures 10D-G, the photocatalytic degradation efficiency of three antibiotics for $\mathrm{Fe}(\mathrm{III})-\mathrm{BVO}$ is higher than that of pure BVO. Meanwhile, as an intermediate for the synthesis of pesticides and typical toxic organic compounds, photocatalytic degradation of 2,4-DCP possessed important practical significance for the treatment of wastewater.

\section{$\mathrm{ZnFeO}_{4}$ and $\mathrm{BiFeO}_{3}$ Based Fenton Catalysts}

$\mathrm{ZnFe}_{2} \mathrm{O}_{4}$ is a novel semiconductor, which possesses a band gap of about $1.9 \mathrm{eV}$, showing a visible light response, thus becoming 
A

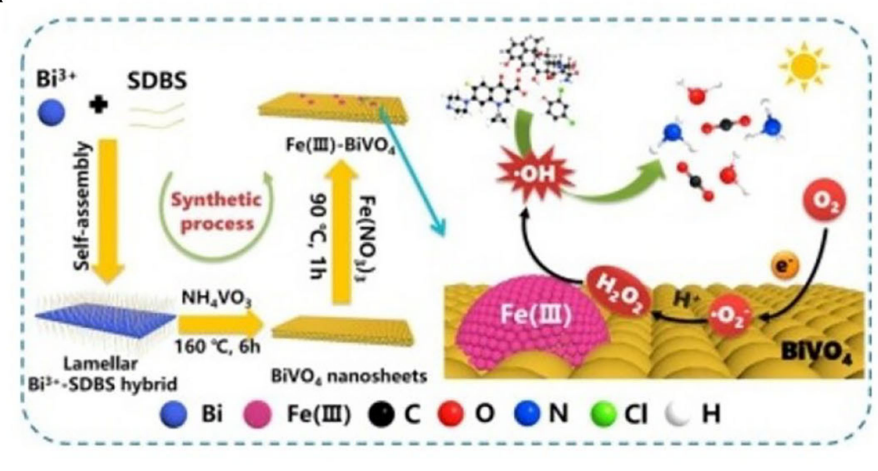

B

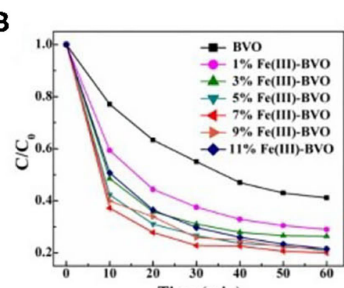

D

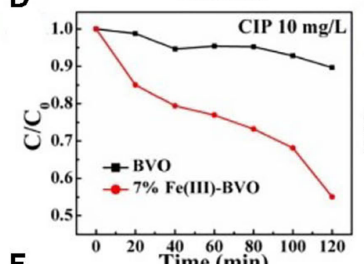

F

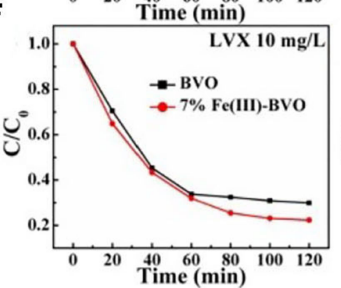

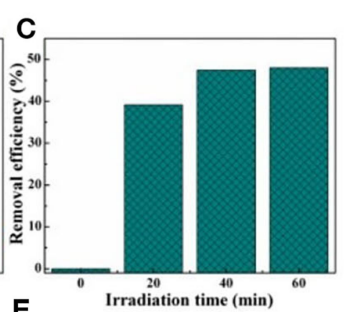

E

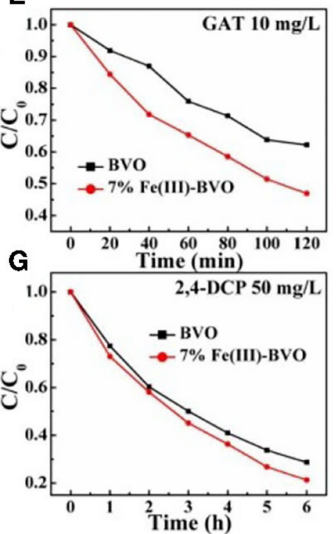

FIGURE 10 | (A) Systematic illustration of preparation method and mechanism; (B) photocatalytic degradation efficiency of TC using various contents of Fe(III)-BVO; (C) Total organic carbon (TOC) removal efficiency of TC by 7\% Fe(III)-BVO photocatalyst and the photocatalytic activity of BVO and 7\% Fe(III)-BVO for the degradation of (D) CIP, (E) GAT, (F) LVX, and (G) 2,4-DCP. Copied with permission (Liu et al., 2017c). Copyright 2019, Elsevier.

attractive in the field of visible light-driven photocatalysis (Sun et al., 2013; Zhu et al., 2016). Accordingly, both $\mathrm{ZnFe}_{2} \mathrm{O}_{4}$ and $\mathrm{ZnFe}_{2} \mathrm{O}_{4}$-based composites can act as photo Fenton-like catalysts to improve the degradation rate of organic pollutants in the presence of $\mathrm{H}_{2} \mathrm{O}_{2}$ (Su et al., 2012; Yao et al., 2014). For instance, Su et al. (2012) reported mesoporous $\mathrm{ZnFe}_{2} \mathrm{O}_{4}$ (meso- $\mathrm{ZnFe}_{2} \mathrm{O}_{4}$ ) prepared by a hydrothermal process. As to photocatalytic degradation of AOII, it showed that AOII almost completely removed in $\mathrm{H}_{2} \mathrm{O}_{2}$ /visible light system after $2 \mathrm{~h}$. It was revealed that high efficiency for AOII degradation was mainly attributed to the strong absorption of $\mathrm{ZnFe}_{2} \mathrm{O}_{4}$ in visible-light region and more generation amount of $\cdot \mathrm{OH}$ by $\mathrm{H}_{2} \mathrm{O}_{2}$. Further, Fu and Wang (2011) reported that they employed a feasible and facile one-step hydrothermal route to fabricate magnetic $\mathrm{ZnFe}_{2} \mathrm{O}_{4}$ graphene nanocomposites. The results showed that as prepared photocatalysts could serve as the photoelectrochemical catalysts for organic pollutants removal and the generator of hydroxyl radicals via the decomposition of $\mathrm{H}_{2} \mathrm{O}_{2}$ under visible light irradiation. Moreover, Chen H. et al. (2017) synthesized $\mathrm{ZnO} / \mathrm{ZnFe}_{2} \mathrm{O}_{4}$ nanocomposite to degrade organic dye in the presence of $\mathrm{H}_{2} \mathrm{O}_{2}$ under near-infrared (NIR) irradiation. It was reported that $\mathrm{ZnO} / \mathrm{ZnFe}_{2} \mathrm{O}_{4}$ nanocomposite performed well for the degradation of methyl orange under either UV, visible or NIR irradiation.

Besides $\mathrm{ZnFe}_{2} \mathrm{O}_{4}$-based nanocomposites, it is also discovered that $\mathrm{BiFeO}_{3}$ perform as well in photo-Fenton like process. Generally, $\mathrm{BiFeO}_{3}$ is recognized as one of the important semiconductors, which possess the ability for visible light response. Additionally, $\mathrm{BiFeO}_{3}$ is widely accepted to be a promising visible-light-response photocatalyst for organic pollutant removal and hydrogen production (Bharathkumar et al., 2016). In Fenton-like process, Di et al. (2019) constructed $\mathrm{Z}$-scheme heterojunction $\mathrm{Ag}_{2} \mathrm{~S}_{\mathrm{BiFeO}}$. The morphology of $\mathrm{Ag}_{2} \mathrm{~S} / \mathrm{BiFeO}_{3}$ was characterized by DF-STEM (Figure 11A). The corresponding elemental maps displayed as well. It showed a uniform elemental distribution of $\mathrm{Bi}, \mathrm{Fe}, \mathrm{O}$ and elements $\mathrm{Ag}$ and $\mathrm{S}$. The result suggested that the $\mathrm{Ag}_{2} \mathrm{~S}$ nanoparticles have been successfully loaded onto the surface of $\mathrm{BiFeO}_{3}$. Further, the photocatalytic and photo-Fenton efficiency was tested in Figures 11B,C, respectively. It was found that MO degradation was significantly enhanced with the addition of catalysts and $\mathrm{H}_{2} \mathrm{O}_{2}$. The specific mechanism of photocatalytic process and photo-Fenton process have been explained in Figures 11D,E. As far as known, the improved efficiency by photo-Fenton process mainly originated from the reduction of $\mathrm{Fe}^{3+}$ ions by photo-generated electrons, thus promoting the decomposition rate of $\mathrm{H}_{2} \mathrm{O}_{2}$. In addition, An et al. (2013a) prepared a nanoscale composite of $\mathrm{BiFeO}_{3}$ and graphene, and used this composite to degrade tetrabromobisphenol A by photo-Fentonlike process, which showed that the graphene- $\mathrm{BiFeO}_{3}$ composite exhibiting higher catalytic ability. Moreover, some researchers have found that $\mathrm{BiFeO}_{3}$-based nanomaterials not only work on photo-Fenton process, but also perform well in sulfate radical based Advanced Oxidation Process (SR-AOP), revealing its vast potential in the field of wastewater treatment.

As above mentioned, some other novel Ag-based nanomaterials, $\mathrm{BiVO}_{4}$-based nanomaterials, $\mathrm{ZnFeO}_{4}$ and $\mathrm{BiF} \mathrm{eO}_{3}$ based nanocomposites were elucidated that effectively 
A
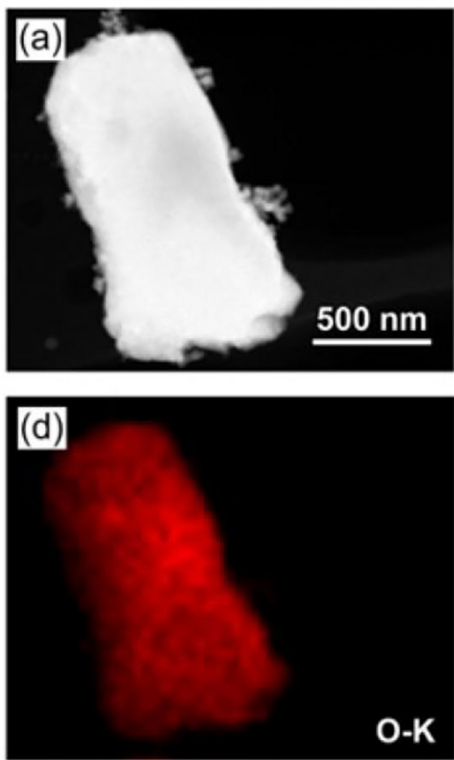

B

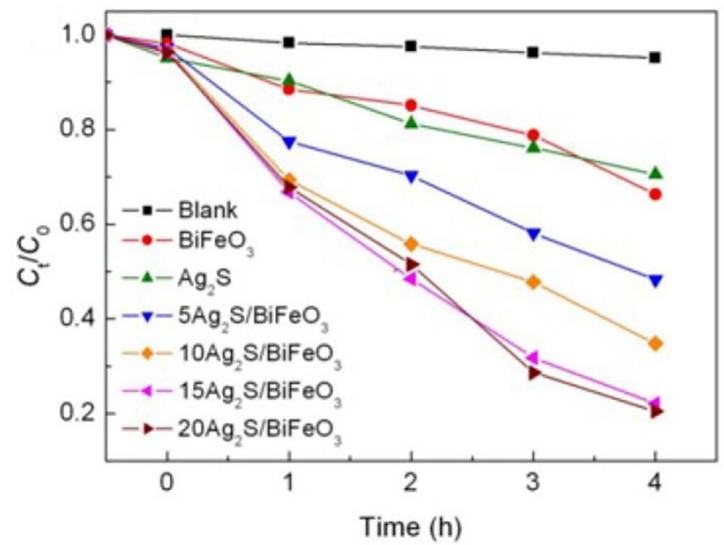

D

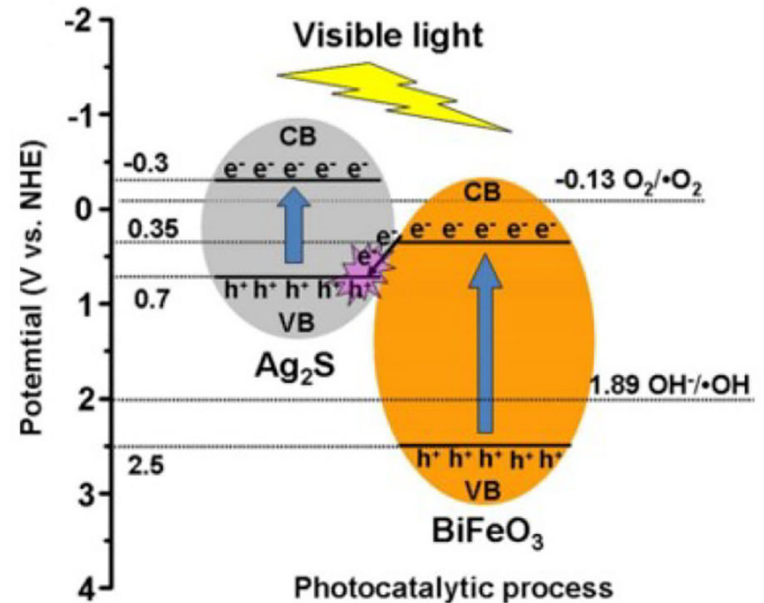

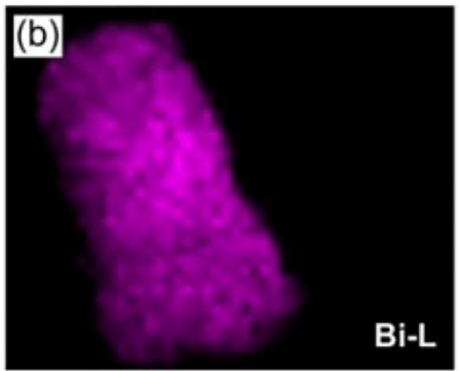
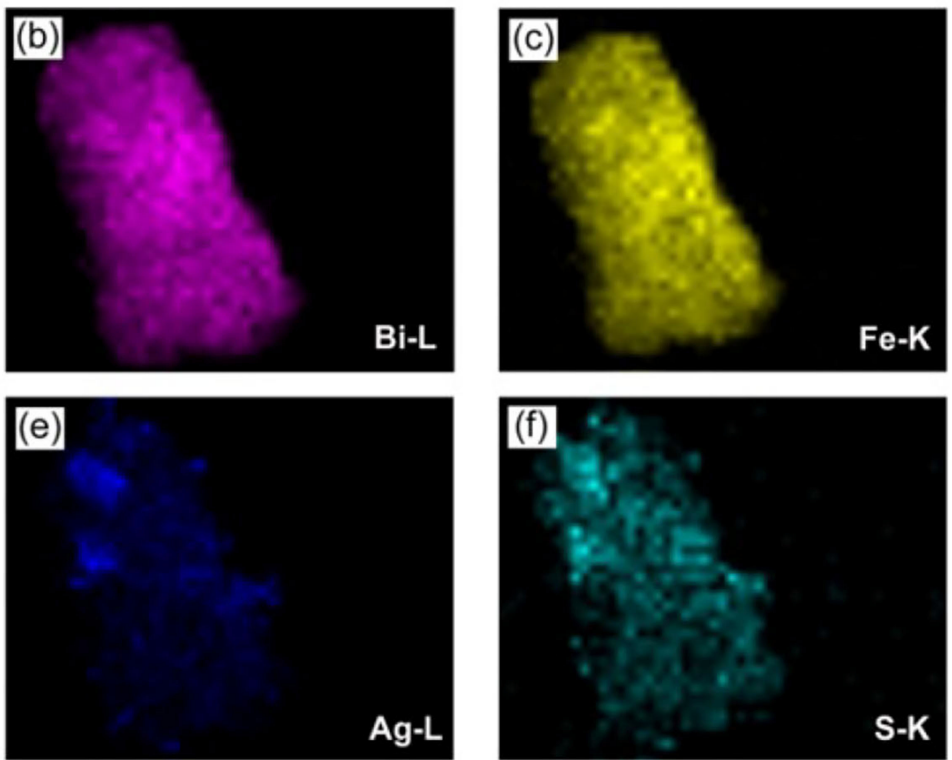

C

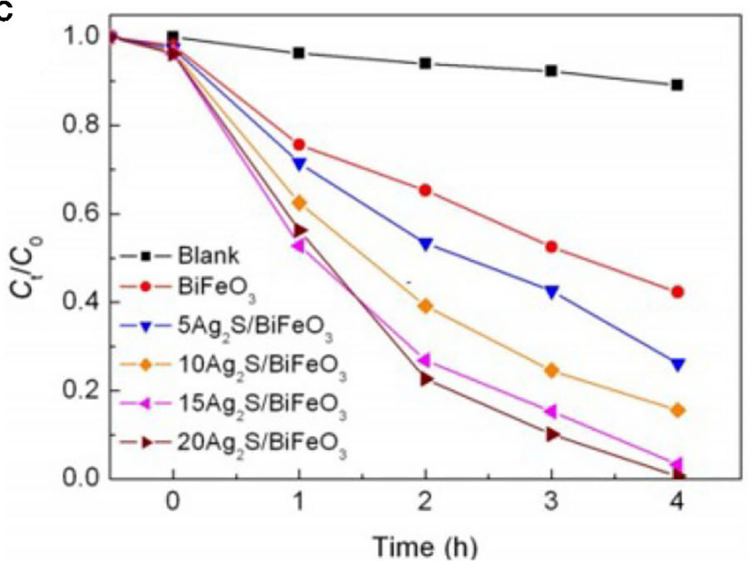

E

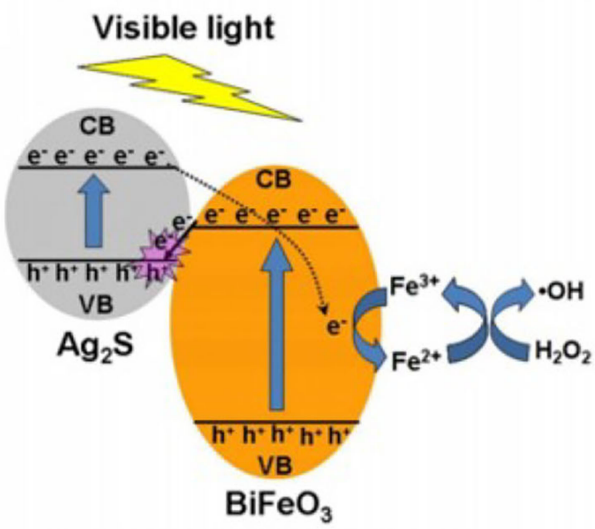

Photo-Fenton catalytic process

FIGURE 11 | (A) Dark-field scanning TEM image of $15 \% \mathrm{Ag}_{2} \mathrm{~S}_{\mathrm{BiFeO}}$; (b-f) Corresponding elemental mapping images; (B) Photocatalytic activities of $\mathrm{Ag}_{2} \mathrm{~S}$, $\mathrm{BiFeO}{ }_{3}$ and $\mathrm{Ag}_{2} \mathrm{~S} / \mathrm{BiFeO}_{3}$ composites for the degradation of $\mathrm{MO}$ under visible-light irradiation; (C) Photo-Fenton catalytic activities of $\mathrm{BiFeO}_{3}$ and $\mathrm{Ag}_{2} \mathrm{~S} / \mathrm{BiFeO}_{3}$ composites for the degradation of $\mathrm{MO}$ in the presence of $\mathrm{H}_{2} \mathrm{O}_{2}$; Possible degradation mechanism of $\mathrm{Ag}_{2} \mathrm{~S} / \mathrm{BiFeO}_{3}$ composites (D) Photocatalytic process; (E) Photo-Fenton catalytic process. Copied with permission (Di et al., 2019). Copyright 2019, MDPI. 
work on photo-Fenton reaction, stemming for their property acting as photocatalysts providing photo-electrons, which was involved in the transformation of $\mathrm{Fe}^{3+} / \mathrm{Fe}^{2+}$. On condition of this, there is no doubt that many other novel semiconductor photocatalyst can synergistically improve efficiency of the Fenton process if acting as the dual catalysts.

\section{CONCLUSIONS AND OUTLOOK}

In the last few decades, the photo-Fenton and photo-Fenton like process have been progressed a lot. The new developed photo-Fenton or photo-Fenton like process present higher efficiency than that of conventional ones. The key to solve the drawbacks of Fenton process is accelerating the transformation of $\mathrm{Fe}^{3+} / \mathrm{Fe}^{2+}$. Facing with this issue, the worldwide scientists have looked for many methodologies. Firstly, the $\mathrm{TiO}_{2}$ and modified $\mathrm{TiO}_{2}$ nanocomposites are able to perform as homogenous or heterogenous photo-Fenton cocatalysts, which focus on speeding up the cycle of $\mathrm{Fe}^{3+} / \mathrm{Fe}^{2+}$, leading to less iron sludge and higher removal efficiency for organic pollutant or bacteria. Secondly, to our best knowledge, graphitic carbon nitride is a new promising candidate in photocatalysis. Various types of iron oxide coupled g- $\mathrm{C}_{3} \mathrm{~N}_{4}$ nanocomposites have been employed in wastewater treatment, VOCs removal and photo-Fenton like membrane separation. Thirdly, graphene is another excellent two-dimensional nanomaterial acting as good support for its good electron transferring capacity and large surface area. On premise that of good activity for 2D structure, three-dimensional graphene-based hydrogel or aerogel have been attempted in photo-Fenton and photo-Fenton like process. As to most of the $3 \mathrm{D}$ structural materials, the water-soluble $\mathrm{Fe}^{2+}$ ions can be easily anchored onto graphene, which explains why the photo-Fenton efficiency presents so good. In addition, some other semiconductors, such as $\mathrm{Ag}, \mathrm{BiVO}_{4}, \mathrm{ZnFeO}_{4}$, and $\mathrm{BiFeO}_{3}$ based nanomaterials have been reviewed briefly as well. In summary, the existing semiconductors, which are equipped with suitable band gap, large surface area, well-separated photogenerated carriers, which no doubt can be promising candidates in photo-Fenton process. Moreover, in recent years, some other alternative nanomaterials, such as metal disulfides, metal carbides, perovskites, etc. are all expected to provide good reference and efficacy in AOPs. However, facing the actual usage

\section{REFERENCES}

An, J., Zhu, L., Wang, N., Song, Z., Yang, Z., Du, D., et al. (2013a). Photo-Fenton like degradation of tetrabromobisphenol A with grapheneBiFeO $\mathrm{O}_{3}$ composite as a catalyst. Chem. Eng. J. 219, 225-237. doi: 10.1016/j.cej.2013.01.013

An, J., Zhu, L., Zhang, Y., and Tang, H. (2013b). Efficient visible light photo-fentonlike degradation of organic pollutants using in situ surface-modified $\mathrm{BiFeO}_{3}$ as a catalyst. J. Environ. Sci. 25, 1213-1225. doi: 10.1016/S1001-0742(12)60172-7

Banić, N., Abramović, B., Krstić, J., Šojić, D., Lončarević, D., Guzsvány, V., et al. (2011). Photodegradation of thiacloprid using $\mathrm{Fe} / \mathrm{TiO}_{2}$ as a heterogeneous photo-Fenton catalyst. Appl. Catal. B Environ. 107, 363-371. doi: 10.1016/j.apcatb.2011.07.037

Bharathkumar, S., Sakar, M., and Balakumar, S. (2016). Experimental evidence for the carrier transportation enhanced visible light driven photocatalytic process in industrial treatment, the sophisticated engineers usually focus more on the nanomaterials whether can be applied in actual sewage treatment on a large scale. Hence, the economic cost, recycling issues and stability need to be paid much attention to in the future development. In the field of actual wastewater treatment, the input energy and economic cost are both factors that we should consider in advance. Due to the injurious to human body and limited wavelength region of UV light, developing visible-light-response photocatalysts is a promising way to rationally treat wastewater, so as it can run at ambient temperature and pressure, utilizing atmospheric oxygen or $\mathrm{H}_{2} \mathrm{O}_{2}$ as oxidant. So far, synthesizing nanomaterials is of high cost, it is of great necessary to synthesize and adopt magnetic nanocomposites, such as $\mathrm{Fe}_{3} \mathrm{O}_{4}$-based and cobalt ferrite-based nanocomposites etc. Moreover, catalyst immobilization, which is closely associated with catalyst recovery and agglomeration, as well as the design of photocatalytic reactor are both key research points in the coming years. One possible strategy is heterogenous photo-Fenton like process with membrane processes (PMRs), and the other one is trying to prolong the contact time between solution and immobilized photocatalyst. Many efforts still need to be made to actual application of photo-Fenton-like process in the future development. If feasible, the nanomaterials in photoFenton-like process is expected to make a huge progress in environmental remediation.

\section{AUTHOR CONTRIBUTIONS}

$\mathrm{CD}$ and $\mathrm{MX}$ conceived the proposal of this manuscript. $\mathrm{CD}$ wrote the paper. MX and JZ gave suggestions on the writing. All authors contributed to the article and approved the submitted version.

\section{FUNDING}

This work was supported by the State Key Research Development Program of China (No. 2016YFA0204200), the National Natural Science Foundation of China (Nos. 21822603, 21677048, 21773062, 5171101651, and 21577036), the Shanghai Pujiang Program (No. 17PJD011), and the Fundamental Research Funds for the Central Universities (Nos. 22221818014 and 22A201514021). in bismuth ferrite $\left(\mathrm{BiFeO}_{3}\right)$ one-dimensional fiber nanostructures. J. Phys. Chem. C 120, 18811-18821. doi: 10.1021/acs.jpcc.6b04344

Chen, C., Zhou, Y., Wang, N., Cheng, L., and Ding, H. (2015). $\mathrm{Cu}_{2}(\mathrm{OH}) \mathrm{PO}_{4} / g-$ $\mathrm{C}_{3} \mathrm{~N}_{4}$ composite as an efficient visible light-activated photo-Fenton photocatalyst. RSC Adv. 5, 95523-95531. doi: 10.1039/C5RA15965B

Chen, H., Liu, W., and Qin, Z. (2017). $\mathrm{ZnO} / \mathrm{ZnFe}_{2} \mathrm{O}_{4}$ nanocomposite as a broadspectrum photo-Fenton-like photocatalyst with near-infrared activity. Catal. Sci. Technol. 7, 2236-2244. doi: 10.1039/C7CY00308K

Chen, Q., Chen, L., Qi, J., Tong, Y., Lv, Y., Xu, C., et al. (2019). Photocatalytic degradation of amoxicillin by carbon quantum dots modified $\mathrm{K}_{2} \mathrm{Ti}_{6} \mathrm{O}_{13}$ nanotubes: effect of light wavelength. Chin. Chem. Lett. 30, 1214-1218. doi: 10.1016/j.cclet.2019.03.002

Chen, Q., Wu, P., Dang, Z., Zhu, N., Li, P., Wu, J., et al. (2010). Iron pillared vermiculite as a heterogeneous photo-Fenton catalyst for photocatalytic 
degradation of azo dye reactive brilliant orange X-GN. Sep. Purif. Technol. 71, 315-323. doi: 10.1016/j.seppur.2009.12.017

Chen, X., Chen, F., Liu, F., Yan, X., Hu, W., Zhang, G., et al. (2016). Ag nanoparticles/hematite mesocrystals superstructure composite: a facile synthesis and enhanced heterogeneous photo-Fenton activity. Catal. Sci. Technol. 6, 4184-4191. doi: 10.1039/C6CY00080K

Chen, X., Lu, W., Xu, T., Li, N., Zhu, Z., Wang, G., et al. (2017). Visible-lightassisted generation of high-valent iron-oxo species anchored axially on g- $\mathrm{C}_{3} \mathrm{~N}_{4}$ for efficient degradation of organic pollutants. Chem. Eng. J. 328, 853-861. doi: 10.1016/j.cej.2017.07.110

Choi, Y. I., Jung, H. J., Shin, W. G., and Sohn, Y. (2015). Band gapengineered $\mathrm{ZnO}$ and $\mathrm{Ag} / \mathrm{ZnO}$ by ball-milling method and their photocatalytic and Fenton-like photocatalytic activities. Appl. Surf. Sci. 356, 615-625. doi: 10.1016/j.apsusc.2015.08.118

Chow, C.-H., and Sze-Yin Leung, K. (2019). Transformations of organic micropollutants undergoing permanganate/bisulfite treatment: kinetics, pathways and toxicity. Chemosphere 237:124524. doi: 10.1016/j.chemosphere.2019.124524

Comer, B. M., and Medford, A. J. (2018). Analysis of photocatalytic nitrogen fixation on rutile $\mathrm{TiO}_{2}(110)$. ACS Sustain. Chem. Eng. 6, 4648-4660. doi: 10.1021 /acssuschemeng.7b03652

Cui, Y., Ding, Z., Liu, P., Antonietti, M., Fu, X., and Wang, X. (2012). Metalfree activation of $\mathrm{H}_{2} \mathrm{O}_{2}$ by $g-\mathrm{C}_{3} \mathrm{~N}_{4}$ under visible light irradiation for the degradation of organic pollutants. Phys. Chem. Chem. Phys. 14, 1455-1462. doi: $10.1039 / \mathrm{C} 1 \mathrm{CP} 22820 \mathrm{~J}$

Di, L., Yang, H., Xian, T., Liu, X., and Chen, X. J. N. (2019). Photocatalytic and photo-Fenton catalytic degradation activities of $\mathrm{Z}$-scheme $\mathrm{Ag}_{2} \mathrm{~S} / \mathrm{BiFeO}_{3}$ heterojunction composites under visible-light irradiation. Nanomater 9:399. doi: 10.3390/nano9030399

Dong, C., Ji, J., Shen, B., Xing, M., and Zhang, J. (2018). Enhancement of $\mathrm{H}_{2} \mathrm{O}_{2}$ decomposition by the co-catalytic effect of WS2 on the Fenton reaction for the synchronous reduction of $\mathrm{Cr}(\mathrm{VI})$ and remediation of phenol. Environ. Sci. Technol. 52, 11297-11308. doi: 10.1021/acs.est. $8 \mathrm{~b} 02403$

Dong, C., Ji, J., Yang, Z., Xiao, Y., Xing, M., and Zhang, J. (2019). Research progress of photocatalysis based on highly dispersed titanium in mesoporous $\mathrm{SiO}_{2}$. Chin. Chem. Lett. 30, 853-862. doi: 10.1016/j.cclet.2019.03.020

Dong, C., Lian, C., Hu, S., Deng, Z., Gong, J., Li, M., et al. (2018a). Sizedependent activity and selectivity of carbon dioxide photocatalytic reduction over platinum nanoparticles. Nat. Commun. 9:1252. doi: 10.1038/s41467-018-03666-2

Dong, C., Liu, J., Xing, M., and Zhang, J. (2018b). Development of titanium oxidebased mesoporous materials in photocatalysis. Res. Chem. Intermediate 44, 7079-7091. doi: 10.1007/s11164-018-3543-5

Dong, C., Lu, J., Qiu, B., Shen, B., Xing, M., and Zhang, J. (2018c). Developing stretchable and graphene-oxide-based hydrogel for the removal of organic pollutants and metal ions. Appl. Catal. B Environ. 222, 146-156. doi: 10.1016/j.apcatb.2017.10.011

Dong, H., Guo, X., and Yin, Y. (2018). A facile synthesis of goethitemodified $\mathrm{g}-\mathrm{C}_{3} \mathrm{~N}_{4}$ composite for photocatalytic degradation of tylosin in an aqueous solution. Res. Chem. Intermediate 44, 3151-3167. doi: $10.1007 / \mathrm{s} 11164-018-3298-\mathrm{z}$

Duan, X., Su, C., Miao, J., Zhong, Y., Shao, Z., Wang, S., et al. (2018). Insights into perovskite-catalyzed peroxymonosulfate activation: maneuverable cobalt sites for promoted evolution of sulfate radicals. Appl. Catal. B Environ. 220, 626-634. doi: 10.1016/j.apcatb.2017.08.088

Esplugas, S., Bila, D. M., Krause, L. G. T., and Dezotti, M. (2007). Ozonation and advanced oxidation technologies to remove endocrine disrupting chemicals (EDCs) and pharmaceuticals and personal care products (PPCPs) in water effluents. J. Hazard. Mater. 149, 631-642. doi: 10.1016/j.jhazmat.2007. 07.073

$\mathrm{Fu}, \mathrm{Y}$., and Wang, X. (2011). Magnetically separable $\mathrm{ZnFe}_{2} \mathrm{O}_{4}$-graphene catalyst and its high photocatalytic performance under visible light irradiation. Ind. Eng. Chem. Res. 50, 7210-7218. doi: 10.1021/ie200162a

Fujishima, A., and Honda, K. J. N. (1972). Electrochemical photolysis of water at a semiconductor electrode. Nature 238, 37-38. doi: 10.1038/238037a0

Gao, X., Ma, C., Liu, Y., Xing, L., and Yan, Y. (2019). Self-induced Fenton reaction constructed by $\mathrm{Fe}(\mathrm{III})$ grafted $\mathrm{BiVO}_{4}$ nanosheets with improved photocatalytic performance and mechanism insight. Appl. Surf. Sci. 467-468, 673-683. doi: 10.1016/j.apsusc.2018.10.172

Giannakis, S., López, M. I. P., Spuhler, D., Pérez, J. A. S., Ibáñez, P. F., and Pulgarin, C. (2016). Solar disinfection is an augmentable, in situ-generated photo-Fenton reaction-part 2: a review of the applications for drinking water and wastewater disinfection. Appl. Catal. B Environ. 198, 431-446. doi: 10.1016/j.apcatb.2016.06.007

Guo, K., Zhang, J., Li, A., Xie, R., Liang, Z., Wang, A., et al. (2018). Ultraviolet irradiation of permanganate enhanced the oxidation of micropollutants by producing HO- and reactive manganese species. Environ. Sci. Technol. Lett. 5, 750-756. doi: 10.1021/acs.estlett.8b00402

Guo, S., Zhang, G., Guo, Y., and Yu, J. C. (2013). Graphene oxide- $\mathrm{Fe}_{2} \mathrm{O}_{3}$ hybrid material as highly efficient heterogeneous catalyst for degradation of organic contaminants. Carbon 60, 437-444. doi: 10.1016/j.carbon.2013. 04.058

Guo, S., Zhu, Y., Yan, Y., Min, Y., Fan, J., and Xu, Q. (2016). Holey structured graphitic carbon nitride thin sheets with edge oxygen doping via photo-Fenton reaction with enhanced photocatalytic activity. Appl. Catal. B Environ. 185, 315-321. doi: 10.1016/j.apcatb.2015.11.030

Guo, T., Wang, K., Zhang, G., and Wu, X. (2019). A novel $\alpha-\mathrm{Fe}_{2} \mathrm{O}_{3} @ g$ $\mathrm{C}_{3} \mathrm{~N}_{4}$ catalyst: synthesis derived from Fe-based MOF and its superior photoFenton performance. Appl. Surf. Sci. 469, 331-339. doi: 10.1016/j.apsusc.2018. 10.183

He, D., Chen, Y., Situ, Y., Zhong, L., and Huang, H. (2017). Synthesis of ternary g- $\mathrm{C}_{3} \mathrm{~N}_{4} / \mathrm{Ag} / \gamma$-FeOOH photocatalyst: an integrated heterogeneous Fenton-like system for effectively degradation of azo dye methyl orange under visible light. Appl. Surf. Sci. 425, 862-872. doi: 10.1016/j.apsusc.2017.06.124

Hu, J., Zhang, P., An, W., Liu, L., Liang, Y., and Cui, W. (2019). In-situ Fe-doped g$\mathrm{C}_{3} \mathrm{~N}_{4}$ heterogeneous catalyst via photocatalysis-Fenton reaction with enriched photocatalytic performance for removal of complex wastewater. Appl. Catal. B Environ. 245, 130-142. doi: 10.1016/j.apcatb.2018.12.029

Hu, J.-Y., Tian, K., and Jiang, H. (2016). Improvement of phenol photodegradation efficiency by a combined g- $\mathrm{C}_{3} \mathrm{~N}_{4} / \mathrm{Fe}(\mathrm{III}) /$ persulfate system. Chemosphere 148 , 34-40. doi: 10.1016/j.chemosphere.2016.01.002

Ikehata, K., and Li, Y. (2018). "Chapter 5-ozone-based processes," in Advanced Oxidation Processes for Waste Water Treatment, eds S. C. Ameta and R. Ameta (Fountain Valley, CA: Academic Press), 115-134.

Jain, B., Singh, A. K., Kim, H. Lichtfouse, E., Sharma, V. K. (2018). Treatment of organic pollutants by homogeneous and heterogeneous Fenton reaction processes. Environ. Chem. Lett. 16, 947-967. doi: 10.1007/s10311-018-0738-3

Jelic, A., Gros, M., Ginebreda, A., Cespedes-Sánchez, R., Ventura, F., Petrovic, M., et al. (2011). Occurrence, partition and removal of pharmaceuticals in sewage water and sludge during wastewater treatment. Water Res. 45, 1165-1176. doi: 10.1016/j.watres.2010.11.010

Jia, Y., Wu, C., Kim, D.-H., Lee, B. W., Rhee, S. J., Park, Y. C., et al. (2018). Nitrogen doped $\mathrm{BiFeO}_{3}$ with enhanced magnetic properties and photo-Fenton catalytic activity for degradation of bisphenol a under visible light. Chem. Eng. J. 337, 709-721. doi: 10.1016/j.cej.2017.12.137

Khadgi, N., and Upreti, A. R. (2019). Photocatalytic degradation of microcystinLR by visible light active and magnetic, $\mathrm{ZnFe}_{2} \mathrm{O}_{4}-\mathrm{Ag} / \mathrm{rGO}$ nanocomposite and toxicity assessment of the intermediates. Chemosphere 221, 441-451. doi: 10.1016/j.chemosphere.2019.01.046

Khan, A. H., Kim, J., Sumarah, M., Macfie, S. M., and Ray, M. B. (2017). Toxicity reduction and improved biodegradability of benzalkonium chlorides by ozone/hydrogen peroxide advanced oxidation process. Sep. Purif. Technol. 185, 72-82. doi: 10.1016/j.seppur.2017.05.010

Kim, H.-E., Lee, J., Lee, H., and Lee, C. (2012). Synergistic effects of $\mathrm{TiO}_{2}$ photocatalysis in combination with Fenton-like reactions on oxidation of organic compounds at circumneutral pH. Appl. Catal. B Environ. 115-116, 219-224. doi: 10.1016/j.apcatb.2011.12.027

Kim, J. R., and Kan, E. (2015). Heterogeneous photo-Fenton oxidation of methylene blue using CdS-carbon nanotube/ $/ \mathrm{TiO}_{2}$ under visible light. J. Ind. Eng. Chem. 21, 644-652. doi: 10.1016/j.jiec.2014.03.032

Klamerth, N., Malato, S., Agüera, A., and Fernández-Alba, A. (2013). PhotoFenton and modified photo-Fenton at neutral $\mathrm{pH}$ for the treatment of emerging contaminants in wastewater treatment plant effluents: a comparison. Water Res. 47, 833-840. doi: 10.1016/j.watres.2012. 11.008 
Lan, H., Wang, F., Lan, M., An, X., Liu, H., and Qu, J. (2019). Hydrogenbond-mediated self-assembly of carbon-nitride-based photo-Fenton-like membranes for wastewater treatment. Environ. Sci. Technol. 53, 6981-6988. doi: 10.1021/acs.est.9b00790

Leary, R., and Westwood, A. (2011). Carbonaceous nanomaterials for the enhancement of $\mathrm{TiO}_{2}$ photocatalysis. Carbon 49, 741-772. doi: 10.1016/j.carbon.2010.10.010

Lee, Y., and von Gunten, U. (2010). Oxidative transformation of micropollutants during municipal wastewater treatment: comparison of kinetic aspects of selective (chlorine, chlorine dioxide, ferrateVI, and ozone) and non-selective oxidants (hydroxyl radical). Water Res. 44, 555-566. doi: 10.1016/j.watres.2009.11.045

Lei, X., You, M., Pan, F., Liu, M., Yang, P., Xia, D., et al. (2019). CuFe $\mathrm{O}_{4} @ G O$ nanocomposite as an effective and recoverable catalyst of peroxymonosulfate activation for degradation of aqueous dye pollutants. Chin. Chem. Lett. 30, 2216-2220. doi: 10.1016/j.cclet.2019.05.039

Li, C., Wang, T., Zhao, Z.-J., Yang, W., Li, J.-F., Li, A., et al. (2018). Promoted fixation of molecular nitrogen with surface oxygen vacancies on plasmonenhanced $\mathrm{TiO}_{2}$ photoelectrodes. Angew. Chem. Int. Ed. 57, 5278-5282. doi: 10.1002/anie.201713229

Li, X., Liu, S., Cao, D., Mao, R., and Zhao, X. (2018). Synergetic activation of $\mathrm{H}_{2} \mathrm{O}_{2}$ by photo-generated electrons and cathodic Fenton reaction for enhanced selfdriven photoelectrocatalytic degradation of organic pollutants. Appl. Catal. B Environ. 235, 1-8. doi: 10.1016/j.apcatb.2018.04.042

Li, Y., Ouyang, S., Xu, H., Wang, X., Bi, Y., Zhang, Y., et al. (2016). Constructing solid-gas-interfacial Fenton reaction over alkalinized- $\mathrm{C}_{3} \mathrm{~N}_{4}$ photocatalyst to achieve apparent quantum yield of $49 \%$ at $420 \mathrm{~nm}$. J. Am. Chem. Soc. 138, 13289-13297. doi: 10.1021/jacs.6b07272

Liu, R., Xu, Y., and Chen, B. (2018). Self-assembled nano-FeO(OH)/reduced graphene oxide aerogel as a reusable catalyst for photo-fenton degradation of phenolic organics. Environ. Sci. Technol. 52, 7043-7053. doi: 10.1021/acs.est.8b01043

Liu, Y., Jin, W., Zhao, Y., Zhang, G., and Zhang, W. (2017a). Enhanced catalytic degradation of methylene blue by $\alpha-\mathrm{Fe}_{2} \mathrm{O}_{3} /$ graphene oxide via heterogeneous photo-Fenton reactions. Appl. Catal. B Environ. 206, 642-652. doi: 10.1016/j.apcatb.2017.01.075

Liu, Y., Liu, X., Zhao, Y., and Dionysiou, D. D. (2017b). Aligned $\alpha-F e O O H$ nanorods anchored on a graphene oxide-carbon nanotubes aerogel can serve as an effective Fenton-like oxidation catalyst. Appl. Catal. B Environ. 213, 74-86. doi: 10.1016/j.apcatb.2017.05.019

Liu, Y., Mao, Y., Tang, X., Xu, Y., Li, C., and Li, F. (2017c). Synthesis of $\mathrm{Ag} / \mathrm{AgCl} / \mathrm{Fe}-\mathrm{S}$ plasmonic catalyst for bisphenol A degradation in heterogeneous photo-Fenton system under visible light irradiation. Chin. J. Catal. 38, 1726-1735. doi: 10.1016/S1872-2067(17)62902-4

Luo, W., Zhu, L., Wang, N., Tang, H., Cao, M., She, Y. J. E., et al. (2010). Efficient removal of organic pollutants with magnetic nanoscaled $\mathrm{BiFeO}_{3}$ as a reusable heterogeneous Fenton-like catalyst. Environ. Sci. Technol. 44, 1786-1791. doi: 10.1021/es903390g

Ma, J., Yang, Q., Wen, Y., and Liu, W. (2017). Fe-g- $\mathrm{C}_{3} \mathrm{~N}_{4}$ /graphitized mesoporous carbon composite as an effective Fenton-like catalyst in a wide $\mathrm{pH}$ range. Appl. Catal. B Environ. 201, 232-240. doi: 10.1016/j.apcatb.2016.08.048

Ma, M., Chen, L., Zhao, J., Liu, W., and Ji, H. (2019). Efficient activation of peroxymonosulfate by hollow cobalt hydroxide for degradation of ibuprofen and theoretical study. Chin. Chem. Lett. 30, 2191-2195. doi: 10.1016/j.cclet.2019.09.031

Matzek, L. W., and Carter, K. E. (2016). Activated persulfate for organic chemical degradation: a review. Chemosphere 151, 178-188. doi: 10.1016/j.chemosphere.2016.02.055

Mayorov, A. S., Gorbachev, R. V., Morozov, S. V., Britnell, L., Jalil, R., Ponomarenko, L. A., et al. (2011). Micrometer-scale ballistic transport in encapsulated graphene at room temperature. Nano. Lett. 11, 2396-2399. doi: $10.1021 / \mathrm{nl} 200758 \mathrm{~b}$

Nair, R. R., Blake, P., Grigorenko, A. N., Novoselov, K. S., Booth, T. J., Stauber, T., et al. (2008). Fine structure constant defines visual transparency of graphene. Science 320:1308. doi: 10.1126/science. 1156965

Ojha, D. P., Joshi, M. K., and Kim, H. J. (2017). Photo-Fenton degradation of organic pollutants using a zinc oxide decorated iron oxide/reduced graphene oxide nanocomposite. Ceram. Int. 43, 1290-1297. doi: 10.1016/j.ceramint.2016.10.079

Ortega-Liébana, M. C., Sánchez-López, E., Hidalgo-Carrillo, J., Marinas, A., Marinas, J. M., Urbano, F. J. (2012). A comparative study of photocatalytic degradation of 3-chloropyridine under UV and solar light by homogeneous (photo-Fenton) and heterogeneous $\left(\mathrm{TiO}_{2}\right)$ photocatalysis. Appl. Catal. B Environ. 127, 316-322. doi: 10.1016/j.apcatb.2012. 08.036

Palanivel, B., Mudisoodum perumal, S. d., Maiyalagan, T., Jayarman, V., Ayyappan, C., and Alagiri, M. (2019). Rational design of $\mathrm{ZnFe}_{2} \mathrm{O}_{4} / g-\mathrm{C}_{3} \mathrm{~N}_{4}$ nanocomposite for enhanced photo-Fenton reaction and supercapacitor performance. Appl. Surf. Sci. 498:143807. doi: 10.1016/j.apsusc.2019.143807

Qian, X., Ren, M., Fang, M., Kan, M., Yue, D., Bian, Z., et al. (2018a). Hydrophilic mesoporous carbon as iron(III)/(II) electron shuttle for visible light enhanced Fenton-like degradation of organic pollutants. Appl. Catal. B Environ. 231, 108-114. doi: 10.1016/j.apcatb.2018.03.016

Qian, X., Ren, M., Zhu, Y., Yue, D., Han, Y., Jia, J., et al. (2017). Visible light assisted heterogeneous Fenton-Like degradation of organic pollutant via $\alpha$ FeOOH/mesoporous carbon composites. Environ. Sci. Technol. 51, 3993-4000. doi: 10.1021/acs.est.6b06429

Qian, X., Wu, Y., Kan, M., Fang, M., Yue, D., Zeng, J., et al. (2018b). FeOOH quantum dots coupled $\mathrm{g}-\mathrm{C}_{3} \mathrm{~N}_{4}$ for visible light driving photo-Fenton degradation of organic pollutants. Appl. Catal. B Environ. 237, 513-520. doi: 10.1016/j.apcatb.2018.05.074

Qiu, B., Deng, Y., Du, M., Xing, M., and Zhang, J. (2016a). Ultradispersed cobalt ferrite nanoparticles assembled in graphene aerogel for continuous photoFenton reaction and enhanced lithium storage performance. Sci. Rep. 6:29099. doi: 10.1038/srep29099

Qiu, B., Li, Q., Shen, B., Xing, M., and Zhang, J. (2016b). Stöber-like method to synthesize ultradispersed $\mathrm{Fe}_{3} \mathrm{O}_{4}$ nanoparticles on graphene with excellent photo-Fenton reaction and high-performance lithium storage. Appl. Catal. B Environ. 183, 216-223. doi: 10.1016/j.apcatb.2015.10.053

Qiu, B., Xing, M., and Zhang, J. (2015). Stöber-like method to synthesize ultralight, porous, stretchable $\mathrm{Fe}_{2} \mathrm{O}_{3}$ /graphene aerogels for excellent performance in photo-Fenton reaction and electrochemical capacitors. J. Mater. Chem. A 3, 12820-12827. doi: 10.1039/C5TA02675J

Rincón, A.-G., and Pulgarin, C. (2004a). Bactericidal action of illuminated $\mathrm{TiO}_{2}$ on pure Escherichia coli and natural bacterial consortia: post-irradiation events in the dark and assessment of the effective disinfection time. Appl. Catal. B Environ. 49, 99-112. doi: 10.1016/j.apcatb.2003.11.013

Rincón, A.-G., and Pulgarin, C. (2004b). Effect of pH, inorganic ions, organic matter and $\mathrm{H}_{2} \mathrm{O}_{2}$ on $E$. coli $\mathrm{K} 12$ photocatalytic inactivation by $\mathrm{TiO}_{2}$ : implications in solar water disinfection. Appl. Catal. B Environ. 51, 283-302. doi: 10.1016/j.apcatb.2004.03.007

Rincón, A.-G., and Pulgarin, C. (2006). Comparative evaluation of $\mathrm{Fe}^{3+}$ and $\mathrm{TiO}_{2}$ photoassisted processes in solar photocatalytic disinfection of water. Appl. Catal. B Environ. 63, 222-231. doi: 10.1016/j.apcatb.2005.10.009

Safaei-Ghomi, J., Akbarzadeh, Z., and Teymuri, R. (2019). ZnS nanoparticles immobilized on graphitic carbon nitride as a recyclable and environmentally friendly catalyst for synthesis of 3-cinnamoyl coumarins. Res. Chem. Intermediate 45, 3425-3439. doi: 10.1007/s11164-01903800-9

Sahar, S., Zeb, A., Liu, Y., Ullah, N., and Xu, A. (2017). Enhanced Fenton, photo-Fenton and peroxidase-like activity and stability over $\mathrm{Fe}_{3} \mathrm{O}_{4} / g-\mathrm{C}_{3} \mathrm{~N}_{4}$ nanocomposites. Chin. J. Catal. 38, 2110-2119. doi: 10.1016/S1872-2067(17)62957-7

Saleh, R., and Taufik, A. (2019). Degradation of methylene blue and congo-red dyes using Fenton, photo-Fenton, sono-Fenton, and sonophotoFenton methods in the presence of iron(II,III) oxide/zinc oxide/graphene $\left(\mathrm{Fe}_{3} \mathrm{O}_{4} / \mathrm{ZnO} /\right.$ graphene) composites. Sep. Purif. Technol. 210, 563-573. doi: 10.1016/j.seppur.2018.08.030

Shao, P., Duan, X., Xu, J., Tian, J., Shi, W., Gao, S., et al. (2017). Heterogeneous activation of peroxymonosulfate by amorphous boron for degradation of bisphenol S. J. Hazard. Mater. 322, 532-539. doi: 10.1016/j.jhazmat.2016.10.020

Shayegan, Z., Lee, C.-S., and Haghighat, F. (2018). $\mathrm{TiO}_{2}$ photocatalyst for removal of volatile organic compounds in gas phase -a review. Chem. Eng. J. 334, 2408-2439. doi: 10.1016/j.cej.2017.09.153 
Shen, B., Dong, C., Ji, J., Xing, M., and Zhang, J. (2019). Efficient Fe(III)/Fe(II) cycling triggered by $\mathrm{MoO}_{2}$ in Fenton reaction for the degradation of dye molecules and the reduction of $\mathrm{Cr}(\mathrm{VI})$. Chin. Chem. Lett. 30, 2205-2210. doi: 10.1016/j.cclet.2019.09.052

Su, M., He, C., Sharma, V. K., Abou Asi, M., Xia, D., Li, X. Z., et al. (2012). Mesoporous zinc ferrite: synthesis, characterization, and photocatalytic activity with $\mathrm{H}_{2} \mathrm{O}_{2}$ /visible light. J. Hazard. Mater. 211, 95-103. doi: 10.1016/j.jhazmat.2011.10.006

Sui, Z., Meng, Q., Zhang, X., Ma, R., and Cao, B. (2012). Green synthesis of carbon nanotube-graphene hybrid aerogels and their use as versatile agents for water purification. J. Mater. Chem. 22, 8767-8771. doi: 10.1039/c2jm00055e

Sun, T., Gong, M., Cai, Y., Zhang, L., Xu, Z., Zhang, D., et al. (2020). MCM41-supported $\mathrm{Fe}(\mathrm{Mn}) / \mathrm{Cu}$ bimetallic heterogeneous catalysis for enhanced and recyclable photo-Fenton degradation of methylene blue. Res. Chem. Intermediate 46, 459-474. doi: 10.1007/s11164-019-03960-8

Sun, Y., Wang, W., Zhang, L., Sun, S., and Gao, E. (2013). Magnetic $\mathrm{ZnFe}_{2} \mathrm{O}_{4}$ octahedra: synthesis and visible light induced photocatalytic activities. Mater. Lett. 98, 124-127. doi: 10.1016/j.matlet.2013.02.014

Tan, C., Gao, N., Fu, D., Deng, J., and Deng, L. (2017). Efficient degradation of paracetamol with nanoscaled magnetic $\mathrm{CoFe}_{2} \mathrm{O}_{4}$ and $\mathrm{MnFe}_{2} \mathrm{O}_{4}$ as a heterogeneous catalyst of peroxymonosulfate. Sep. Purif. Technol. 175, 47-57. doi: 10.1016/j.seppur.2016.11.016

Tang, C. Y., Yang, Z., Guo, H., Wen, J. J., Nghiem, L. D., and Cornelissen, E. (2018). Potable water reuse through advanced membrane technology. Environ. Sci. Technol. 52, 10215-10223. doi: 10.1021/acs.est.8b00562

ThanhThuy, T. T., Feng, H., and Cai, Q. (2013). Photocatalytic degradation of pentachlorophenol on $\mathrm{ZnSe} / \mathrm{TiO}_{2}$ supported by photo-Fenton system. Chem. Eng. J. 223, 379-387. doi: 10.1016/j.cej.2013.03.025

Tryba, B., Morawski, A. W., Inagaki, M., and Toyoda, M. (2006). Mechanism of phenol decomposition on $\mathrm{FeC} \mathrm{TiO}_{2}$ and $\mathrm{Fe} \mathrm{TiO}_{2}$ photocatalysts via photo-Fenton process. J. Photochem. Photobio. A Chem. 179, 224-228. doi: 10.1016/j.jphotochem.2005.08.019

Vaiano, V., Sacco, O., Sannino, D., and Ciambelli, P. (2015). Nanostructured Ndoped $\mathrm{TiO}_{2}$ coated on glass spheres for the photocatalytic removal of organic dyes under UV or visible light irradiation. Appl. Catal. B Environ. 170-171, 153-161. doi: 10.1016/j.apcatb.2015.01.039

Wang, H., Xu, Y., Jing, L., Huang, S., Zhao, Y., He, M., et al. (2017). Novel magnetic $\mathrm{BaFe}_{12} \mathrm{O}_{19} / \mathrm{g}-\mathrm{C}_{3} \mathrm{~N}_{4}$ composites with enhanced thermocatalytic and photo-Fenton activity under visible-light. J. Alloy. Compd. 710, 510-518. doi: 10.1016/j.jallcom.2017.03.144

Wang, J., and Wang, S. (2018). Activation of persulfate (PS) and peroxymonosulfate (PMS) and application for the degradation of emerging contaminants. Chem. Eng. J. 334, 1502-1517. doi: 10.1016/j.cej.2017.11.059

Wang, L., Jiang, J., Pang, S.-Y., Gao, Y., Zhou, Y., Li, J., et al. (2019). Further insights into the combination of permanganate and peroxymonosulfate as an advanced oxidation process for destruction of aqueous organic contaminants. Chemosphere 228, 602-610. doi: 10.1016/j.chemosphere.2019. 04.149

Wang, P., Wang, L., Sun, Q., Qiu, S., Liu, Y., Zhang, X., et al. (2016). Preparation and performance of $\mathrm{Fe}_{3} \mathrm{O}_{4} @$ @hydrophilic graphene composites with excellent Photo-Fenton activity for photocatalysis. Mater. Lett. 183, 61-64. doi: 10.1016/j.matlet.2016.07.080

Wang, P., Zhao, G., Wang, Y., and Lu, Y. (2017). $\mathrm{MnTiO}_{3}$-driven low-temperature oxidative coupling of methane over $\mathrm{TiO}_{2}$-doped $\mathrm{Mn}_{2} \mathrm{O}_{3}-\mathrm{Na}_{2} \mathrm{WO}_{4} / \mathrm{SiO}_{2}$ catalyst. Sci. Adv. 3:e1603180. doi: 10.1126/sciadv.1603180

Wang, Q., Wang, P., Xu, P., Li, Y., Duan, J., Zhang, G., et al. (2020). Visible-lightdriven photo-Fenton reactions using $\mathrm{Zn1}-1.5 \mathrm{xFexS} / \mathrm{g}-\mathrm{C}_{3} \mathrm{~N}_{4}$ photocatalyst: degradation kinetics and mechanisms analysis. Appl. Catal. B Environ. 266:118653. doi: 10.1016/j.apcatb.2020.118653

Wang, Z., Fan, Y., Wu, R., Huo, Y., Wu, H., Wang, F., et al. (2018). Novel magnetic g- $\mathrm{C}_{3} \mathrm{~N}_{4} / \alpha-\mathrm{Fe}_{2} \mathrm{O}_{3} / \mathrm{Fe}_{3} \mathrm{O}_{4}$ composite for the very effective visible-lightFenton degradation of orange II. RSC Adv. 8, 5180-5188. doi: 10.1039/C7RA13 291C

Xi, Z., Li, C., Zhang, L., Xing, M., and Zhang, J. (2014). Synergistic effect of $\mathrm{Cu}_{2} \mathrm{O} / \mathrm{TiO}_{2}$ heterostructure nanoparticle and its high $\mathrm{H}_{2}$ evolution activity. Int. J. Hydrogen Energ. 39, 6345-6353. doi: 10.1016/j.ijhydene.2014.01.209

Xiang, Q., Yu, J., and Jaroniec, M. (2012). Graphene-based semiconductor photocatalysts. Chem. Soc. Rev. 41, 782-796. doi: 10.1039/C1CS15172J
Xing, M., Xu, W., Dong, C., Bai, Y., Zeng, J., Zhou, Y., et al. (2018a). Metal sulfides as excellent co-catalysts for $\mathrm{H}_{2} \mathrm{O}_{2}$ decomposition in advanced oxidation processes. Chem 4, 1359-1372. doi: 10.1016/j.chempr.2018. 03.002

Xing, M., Zhang, J., Qiu, B., Tian, B., Anpo, M., and Che, M. (2015). A brown mesoporous $\mathrm{TiO}_{2}$-x/MCF composite with an extremely high quantum yield of solar energy photocatalysis for $\mathrm{H}_{2}$ evolution. Small 11, 1920-1929. doi: 10.1002/smll.201403056

Xing, M., Zhou, Y., Dong, C., Cai, L., Zeng, L., Shen, B., et al. (2018b). Modulation of the reduction potential of $\mathrm{TiO}_{2}-\mathrm{x}$ by fluorination for efficient and selective $\mathrm{CH} 4$ generation from $\mathrm{CO}_{2}$ photoreduction. Nano. Lett. 18, 3384-3390. doi: 10.1021/acs.nanolett.8b00197

Xu, T., Zhu, R., Zhu, G., Zhu, J., Liang, X., Zhu, Y., et al. (2017). Mechanisms for the enhanced photo-Fenton activity of ferrihydrite modified with $\mathrm{BiVO}_{4}$ at neutral pH. Appl. Catal. B Environ. 212, 50-58. doi: 10.1016/j.apcatb.2017. 04.064

Yang, Z., Ma, X.-H., and Tang, C. Y. (2018). Recent development of novel membranes for desalination. Desalination 434, 37-59. doi: 10.1016/j.desal.2017.11.046

Yang, Z., Wu, Y., Wang, J., Cao, B., and Tang, C. Y. (2016). In situ reduction of silver by polydopamine: a novel antimicrobial modification of a thinfilm composite polyamide membrane. Environ. Sci. Technol. 50, 9543-9550. doi: $10.1021 /$ acs.est.6b01867

Yao, T., Jia, W., Feng, Y., Zhang, J., Lian, Y., Wu, J., et al. (2019). Preparation of reduced graphene oxide nanosheet/ $/ \mathrm{Fe}_{\mathrm{x}} \mathrm{O}_{\mathrm{y}} /$ nitrogen-doped carbon layer aerogel as photo-Fenton catalyst with enhanced degradation activity and reusability. J. Hazard. Mater. 362, 62-71. doi: 10.1016/j.jhazmat.2018. 08.084

Yao, Y., Qin, J., Cai, Y., Wei, F., Lu, F., and Wang, S. (2014). Facile synthesis of magnetic $\mathrm{ZnFe}_{2} \mathrm{O}_{4}$-reduced graphene oxide hybrid and its photo-Fentonlike behavior under visible iradiation. Environ. Sci. Pollut. Res. 21, 7296-7306. doi: $10.1007 / \mathrm{s} 11356-014-2645-\mathrm{x}$

Ye, Y., Yang, H., Wang, X., and Feng, W. (2018). Photocatalytic, Fenton and photo-Fenton degradation of $\mathrm{RhB}$ over Z-scheme g- $\mathrm{C}_{3} \mathrm{~N}_{4} / \mathrm{LaFeO}_{3}$ heterojunction photocatalysts. Mater. Sci. Semicon. Proc. 82, 14-24. doi: 10.1016/j.mssp.2018.03.033

Yu, J., Low, J., Xiao, W., Zhou, P., and Jaroniec, M. (2014). Enhanced photocatalytic $\mathrm{CO}_{2}$-reduction activity of anatase $\mathrm{TiO}_{2}$ by coexposed $\{001\}$ and $\{101\}$ Facets. $J$. Am. Chem. Soc. 136, 8839-8842. doi: 10.1021/ja5044787

Yu, L., Shao, Y., and Li, D. (2017). Direct combination of hydrogen evolution from water and methane conversion in a photocatalytic system over Pt/TiO ${ }_{2}$. Appl. Catal. B Environ. 204, 216-223. doi: 10.1016/j.apcatb.2016. 11.039

Yu, S., Wang, Y., Sun, F., Wang, R., and Zhou, Y. (2018). Novel mpg- $\mathrm{C}_{3} \mathrm{~N}_{4} / \mathrm{TiO}_{2}$ nanocomposite photocatalytic membrane reactor for sulfamethoxazole photodegradation. Chem. Eng. J. 337, 183-192. doi: 10.1016/j.cej.2017. 12.093

Zhang, D., Gersberg, R. M., Ng, W. J., and Tan, S. K. (2014). Removal of pharmaceuticals and personal care products in aquatic plant-based systems: a review. Environ. Pollut. 184, 620-639. doi: 10.1016/j.envpol.2013. 09.009

Zhang, L., Tian, B., Chen, F., and Zhang, J. (2012). Nickel sulfide as cocatalyst on nanostructured $\mathrm{TiO}_{2}$ for photocatalytic hydrogen evolution. Int. J. Hydrogen Energ. 37, 17060-17067. doi: 10.1016/j.ijhydene.2012. 08.120

Zhang, Y.-Y., He, C., Deng, J.-H., Tu, Y.-T., Liu, J.-K., and Xiong, Y. (2009). Photo-Fenton-like catalytic activity of nano-lamellar $\mathrm{Fe}_{2} \mathrm{~V}_{4} \mathrm{O}_{13}$ in the degradation of organic pollutants. Res. Chem. Intermediate 35:727. doi: 10.1007/s11164-009-0090-0

Zhao, J., Ji, M., Di, J., Zhang, Y., He, M., Li, H., et al. (2020). Novel Z-scheme heterogeneous photo-Fenton-like $\mathrm{g}-\mathrm{C}_{3} \mathrm{~N}_{4} / \mathrm{FeOCl}$ for the pollutants degradation under visible light irradiation. J. Photochem. Photobio. A Chem. 391:112343. doi: 10.1016/j.jphotochem.2019. 112343

Zhao, Y., Zhao, Y., Shi, R., Wang, B., Waterhouse, G. I. N., Wu, L.-Z., et al. (2019). Tuning oxygen vacancies in ultrathin $\mathrm{TiO}_{2}$ nanosheets to boost photocatalytic nitrogen fixation up to $700 \mathrm{~nm}$. Adv. Mater. 31:1806482. doi: $10.1002 /$ adma.201806482 
Zhou, L., Wang, L., Zhang, J., Lei, J., and Liu, Y. (2016). Well-dispersed $\mathrm{Fe}_{2} \mathrm{O}_{3}$ nanoparticles on $\mathrm{g}-\mathrm{C}_{3} \mathrm{~N}_{4}$ for efficient and stable Photo-Fenton photocatalysis under visible-light irradiation. Eur. J. Inorg. Chem. 34, 5387-5392. doi: 10.1002/ejic.201600959

Zhou, Y., Yi, Q., Xing, M., Shang, L., Zhang, T., and Zhang, J. (2016). Graphene modified mesoporous titania single crystals with controlled and selective photoredox surfaces. Chem. Commun. 52, 1689-1692. doi: 10.1039/C5CC07 567J

Zhu, K., Wang, J., Wang, Y., Jin, C., and Ganeshraja, A. S. (2016). Visible-lightinduced photocatalysis and peroxymonosulfate activation over $\mathrm{ZnFe}_{2} \mathrm{O}_{4}$ fine nanoparticles for degradation of orange II. Catal. Sci. Technol. 6, 2296-2304. doi: 10.1039/C5CY01735A

Zhu, Y., Zhu, R., Xi, Y., Xu, T., Yan, L., Zhu, J., et al. (2018a). Heterogeneous photoFenton degradation of bisphenol $\mathrm{A}$ over $\mathrm{Ag} / \mathrm{AgCl} /$ ferrihydrite catalysts under visible light. Chem. Eng. J. 346, 567-577. doi: 10.1016/j.cej.2018.04.073
Zhu, Y., Zhu, R., Yan, L., Fu, H., Xi, Y., Zhou, H., et al. (2018b). Visible-light $\mathrm{Ag} / \mathrm{AgBr} /$ ferrihydrite catalyst with enhanced heterogeneous photo-Fenton reactivity via electron transfer from $\mathrm{Ag} / \mathrm{AgBr}$ to ferrihydrite. Appl. Catal. B Environ. 239, 280-289. doi: 10.1016/j.apcatb.2018.08.025

Conflict of Interest: The authors declare that the research was conducted in the absence of any commercial or financial relationships that could be construed as a potential conflict of interest.

Copyright $\odot 2020$ Dong, Xing and Zhang. This is an open-access article distributed under the terms of the Creative Commons Attribution License (CC BY). The use, distribution or reproduction in other forums is permitted, provided the original author(s) and the copyright owner(s) are credited and that the original publication in this journal is cited, in accordance with accepted academic practice. No use, distribution or reproduction is permitted which does not comply with these terms. 